\title{
Cellular and Network Models for Intrathalamic Augmenting Responses During 10-Hz Stimulation
}

\author{
MAXIM BAZHENOV, ${ }^{1}$ IGOR TIMOFEEV,$^{2}$ MIRCEA STERIADE, ${ }^{2}$ AND TERRENCE J. SEJNOWSKI ${ }^{1,3}$ \\ ${ }^{1}$ Howard Hughes Medical Institute, The Salk Institute, Computational Neurobiology Laboratory, La Jolla, \\ California 92037; ${ }^{2}$ Laboratory of Neurophysiology, School of Medicine, Laval University, Quebec G1K 7P4, Canada; \\ and ${ }^{3}$ Department of Biology, University of California San Diego, La Jolla, California 92093
}

\begin{abstract}
Bazhenov, Maxim, Igor Timofeev, Mircea Steriade, and Terrence J. Sejnowski. Cellular and network models for intrathalamic augmenting responses during $10-\mathrm{Hz}$ stimulation. J. Neurophysiol. 79: 2730-2748, 1998. Repetitive stimulation of the thalamus at $7-14 \mathrm{~Hz}$ evokes responses of increasing amplitude in the thalamus and the areas of the neocortex to which the stimulated foci project. Possible mechanisms underlying the thalamic augmenting responses during repetitive stimulation were investigated with computer models of interacting thalamocortical (TC) and thalamic reticular (RE) cells. The ionic currents in these cells were modeled with Hodgkin-Huxley type of kinetics, and the results of the model were compared with in vivo thalamic recordings from decorticated cats. The simplest network model demonstrating an augmenting response was a single pair of coupled RE and TC cells, in which RE-induced inhibitory postsynaptic potentials (IPSPs) in the TC cell led to progressive deinactivation of a low-threshold $\mathrm{Ca}^{2+}$ current. The augmenting responses in two reciprocally interacting chains of RE and TC cells depended also on $\gamma$-aminobutyric acid$\mathrm{B}\left(\mathrm{GABA}_{\mathrm{B}}\right)$ IPSPs. Lateral $\mathrm{GABA}_{\mathrm{A}}$ inhibition between identical RE cells, which weakened bursts in these cells, diminished $\mathrm{GABA}_{B}$ IPSPs and delayed the augmenting response in TC cells. The results of these simulations show that the interplay between existing mechanisms in the thalamus explains the basic properties of the intrathalamic augmenting responses.
\end{abstract}

\section{INTRODUCTION}

Rhythmic 7- to 14-Hz stimulation of the thalamus evokes cortical and thalamic responses that grow in size during the first few stimuli, a phenomenon called the augmenting response (Morison and Dempsey 1943). Early investigations showed that decortication reduced but did not abolish the augmentation of repetitive responses recorded from the thalamus; however, removal of the thalamus abolished the repetitive and augmented responses in the cortex evoked by capsular stimulation (Morison and Dempsey 1943). Later studies reported that stimulation of white matter could elicit responses growing in size in cerebral cortex but their patterns were different from thalamically evoked augmenting waves (Morin and Steriade 1981).

Two types of cortical mechanisms have been proposed to explain augmenting responses, one based on synaptic mechanisms - an enhanced $N$-methyl-D-aspartate (NMDA) response via depression of $\gamma$-aminobutyric acid (GABA) mediated inhibitory postsynaptic potential (IPSP) (Metherate and Ashe 1994) - and a second that depends on the intrinsic properties of bursting layer V cells (Castro-Alamancos and Connors 1996b). Another possible mechanism is short-term synaptic plasticity, as most excitatory synapses between cor- tical pyramidal cortical cells are depressed when stimulated at 7-14 Hz (Castro-Alamancos and Connors 1997; Thomson 1997; Tsodyks and Markram 1997). We will consider these cortical mechanisms in a forthcoming paper (see also, Houweling et al. 1997).

Intrathalamic augmenting responses have been investigated in decorticated animals (Steriade and Timofeev 1997; Timofeev and Steriade 1998) and are different from those found in the cortex. It is known that stimulation of afferent pathways in vitro (Crunelli et al. 1988; Hirsch and Burnod 1987) and in vivo (Paré et al. 1991) leads to $\mathrm{GABA}_{\mathrm{A}^{-}}$and $\mathrm{GABA}_{\mathrm{B}}$-mediated IPSPs. The IPSPs in thalamocortical (TC) cells after the first stimulus in a pulse train at $7-14 \mathrm{~Hz}$ hyperpolarizes the cells and progressively deinactivates lowthreshold $\mathrm{Ca}^{2+}$ currents (Jahnsen and Llinás 1984a,b). TC cells located near the stimulating electrode receive sufficiently large excitatory postsynaptic potentials (EPSPs) so that high-threshold currents are activated (Pedroarena and Llinás 1997). This high-threshold type of augmenting response in the thalamus occurs only when the balance between synaptic excitation and inhibition is shifted toward excitation and occurs only in a limited region surrounding the stimulating electrode (Steriade and Timofeev 1997), whereas the low-threshold type of augmenting response can be found at sites that are distant from the stimulating electrode (Timofeev and Steriade 1998).

In the present study, we investigated the mechanisms underlying the low-threshold augmenting responses found in the thalamus in vivo. Because the properties of thalamic cells are quite complex and the interactions between them produce a wide range of dynamical behaviors, we used compartmental models of interacting TC and thalamic reticular (RE) cells to explore the main features of augmenting responses. The minimal intrathalamic network model capable of generating augmenting responses consisted of one RETC pair. In larger thalamic networks, additional mechanisms became prominent and the low-threshold $\mathrm{Ca}^{2+}$ currents together with $\mathrm{GABA}_{\mathrm{B}}$ IPSPs were the principal mechanisms that generated incremental responses in these models.

\section{METHODS}

\section{Intrinsic currents}

Each TC and RE cell was modeled by a single-compartment that included voltage- and $\mathrm{Ca}^{2+}$-dependent currents described by Hodgkin-Huxley kinetics (Hodgkin and Huxley 1952)

$$
C_{\mathrm{m}} \frac{\mathrm{d} V}{\mathrm{~d} t}=-g_{\mathrm{L}}\left(V-E_{\mathrm{L}}\right)-I^{\mathrm{int}}-I^{\mathrm{syn}}
$$


A

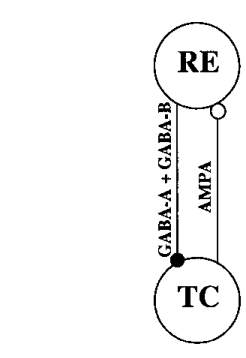

B

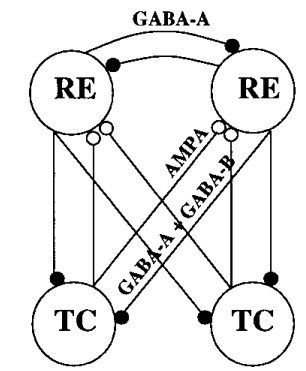

C

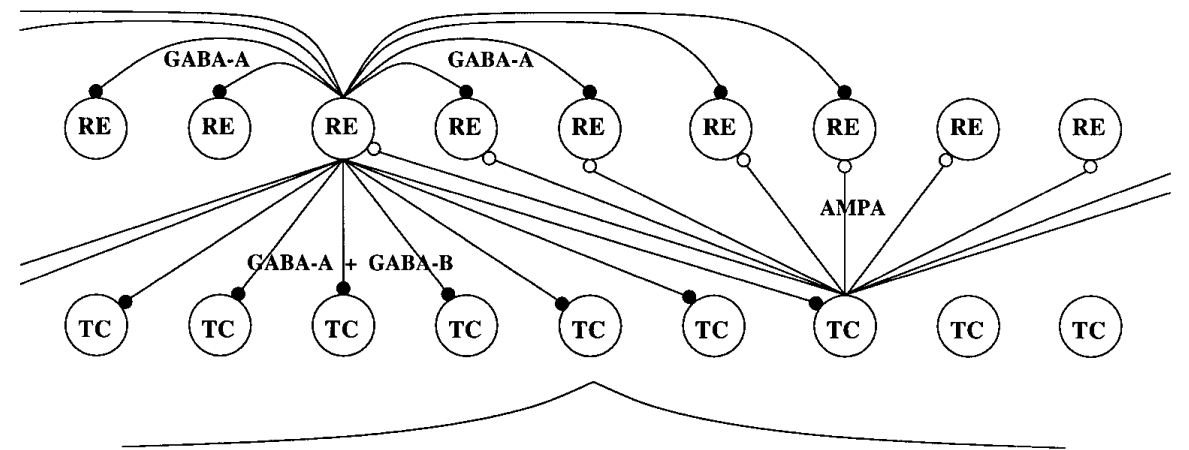

FIG. 1. Structure of synaptic interconnections thalamic reticular (RE)- thalamocortical (TC) networks. $A$ : reciprocal pair of RE-TC cells. $B: 2$ pairs of RE-TC cells. $C$ : 1 -dimensional chain of RE-TC cells. Intensity of stimulation was maximal in the center of the chain and decayed exponentially with distance from the center. $\bigcirc$, excitatory $[\alpha$-amino-3-hydroxy-5-methyl4-isoxazolepropionic acid (AMPA)] synapses; $\bullet$, inhibitory $[\gamma$-aminobutyric acid$\mathrm{A}\left(\mathrm{GABA}_{\mathrm{A}}\right)$ and $\left.\mathrm{B}\left(\mathrm{GABA}_{\mathrm{B}}\right)\right]$ synapses.

\section{STIMULUS INTENSITY}

where $C_{\mathrm{m}}$ is the membrane capacitance, $g_{\mathrm{L}}$ is the leakage conductance, $E_{\mathrm{L}}$ is the reversal potential, $I^{\text {int }}$ is a sum of active intrinsic currents $\left(I_{j}^{\mathrm{int}}\right)$, and $I^{\mathrm{syn}}$ is a sum of synaptic currents $\left(I_{j}^{\mathrm{syn}}\right)$.

For both RE and TC cells. we included a fast sodium current $I_{\mathrm{Na}}$, a fast potassium current $I_{\mathrm{K}}$ (Traub and Miles 1991), a lowthreshold $\mathrm{Ca}^{2+}$ dependent current $I_{\mathrm{T}}$ (Huguenard and McCormick 1992; Huguenard and Prince 1992), and a potassium leak current $I_{\mathrm{KL}}$ (McCormick and Huguenard 1992). A hyperpolarization-activated cation current $I_{\mathrm{h}}$ (Destexhe et al. 1996a; McCormick and Pape 1990) and potassium A current $I_{\mathrm{A}}$ (Huguenard et al. 1991) also were included in TC cells.

All the voltage-dependent ionic currents $I_{j}^{\mathrm{int}}(t)$ had the same general form

$$
I_{j}^{\mathrm{int}}=g_{j} m^{\mathrm{M}} h^{\mathrm{N}}\left(V-E_{j}\right)
$$

where $g_{j}$ is the maximal conductance, $m(t)$ is the activation variable, $h(t)$ is the inactivation variable, and $\left(V-E_{\mathrm{j}}\right)$ is the difference between membrane potential and reversal potential.

The model of $I_{\mathrm{h}}$ current takes into account both voltage and $\mathrm{Ca}^{2+}$ dependencies (Destexhe et al. 1996a). The voltage-dependence is described by the first order kinetics of transitions between closed $C$ and open $O$ states of the channels without inactivation

$$
C \stackrel{\alpha}{\leftrightarrow} \mathrm{O}
$$

where $\alpha(V), \beta(V)$ are the voltage-dependent transition rates.

The $\mathrm{Ca}^{2+}$-dependence is based on higher-order kinetics involving a regulation factor $P$. The binding of the $\mathrm{Ca}^{2+}$ ions with unbound form of the regulation factor $P_{0}$ leads to the bound form $P_{1}$. At the next step $P_{1}$ binds to the open state of the channel $O$ that produces the locked form $O_{\mathrm{L}}$

$$
P_{0}+2 \mathrm{Ca}^{2+} \underset{k_{2}}{\stackrel{k_{1}}{\leftrightarrow}} P_{1}, \quad O+P_{1} \underset{k_{4}}{\stackrel{k_{3}}{\leftrightarrow}} O_{\mathrm{L}}
$$

Both the open and locked states of the channels contribute to the $I_{\mathrm{h}}$ current

$$
I_{\mathrm{h}}=g_{\max }\left([O]+k\left[O_{\mathrm{L}}\right]\right)\left(V-E_{\mathrm{h}}\right)
$$

The equations and values of parameters are given in the APPENDIX.

\section{Synaptic currents}

All synaptic currents were calculated according to

$$
I_{\text {syn }}=g_{\text {syn }}[O]\left(V-E_{\text {syn }}\right)
$$

where $g_{\mathrm{syn}}$ is the maximal conductivity, $E_{\mathrm{syn}}$ is the reversal potential, and $[O](t)$ is the fraction of open channels.

$\mathrm{GABA}_{\mathrm{A}}$ and $\alpha$-amino-3-hydroxy-5-methyl-4-isoxazolepropionic acid (AMPA) synaptic currents were modeled by first-order activation schemes ( see review in Destexhe et al. 1994b). The transmitter $T$ binds to the closed form of receptors $C$ and yields the open form $O$

$$
C+T \underset{\beta}{\stackrel{\alpha}{\leftrightarrow}} O
$$

The concentration of the released transmitter [ $T$ ] was modeled by a brief pulse that is triggered when the presynaptic voltage crosses $0 \mathrm{mV}$.

$\mathrm{GABA}_{\mathrm{B}}$ receptors were modeled by a higher-order reaction scheme that takes into account activation of $\mathrm{K}^{+}$channels by $\mathrm{G}$ proteins (Destexhe et al. 1994b, 1996a; Dutar and Nicoll 1988)

$$
R_{0}+T \underset{r_{2}}{\stackrel{r_{1}}{\leftrightarrow}} R_{1}, \quad G_{0}+R_{1} \underset{r_{4}}{\stackrel{r_{3}}{\leftrightarrow}} G, \quad C+4 G \underset{r_{6}}{\stackrel{r_{5}}{\leftrightarrow}} O
$$

In this scheme, the binding of transmitter $T$ to the receptors $R_{0}$ leads to its activated form $R_{1}$. The inactive form of $\mathrm{G}$ proteins, $G_{0}$, which is supposed to be in excess, transformed to the active form catalyzed by $R_{1}$. Finally when the active form of the $G$ proteins binds to the closed form of the channel at four binding sites, the channel opens, $O$. The assumption of quasistationarity for the last reaction leads to the expression $[O]=[G]^{4} /\left([G]^{4}+K\right)$.

This model $\mathrm{GABA}_{\mathrm{B}}$ synapse yields a strong response for a prolonged burst of spikes in the presynaptic cell. In contrast, a burst with only a few spikes evokes a weak $\mathrm{GABA}_{B}$ IPSP in the postsynaptic cell. The equations and values of parameters are given in the APPENDIX.

\section{Network geometry}

We simulated four network models, one consisting of a single pair of TC-RE cells reciprocally connected (Fig. 1A), a second 

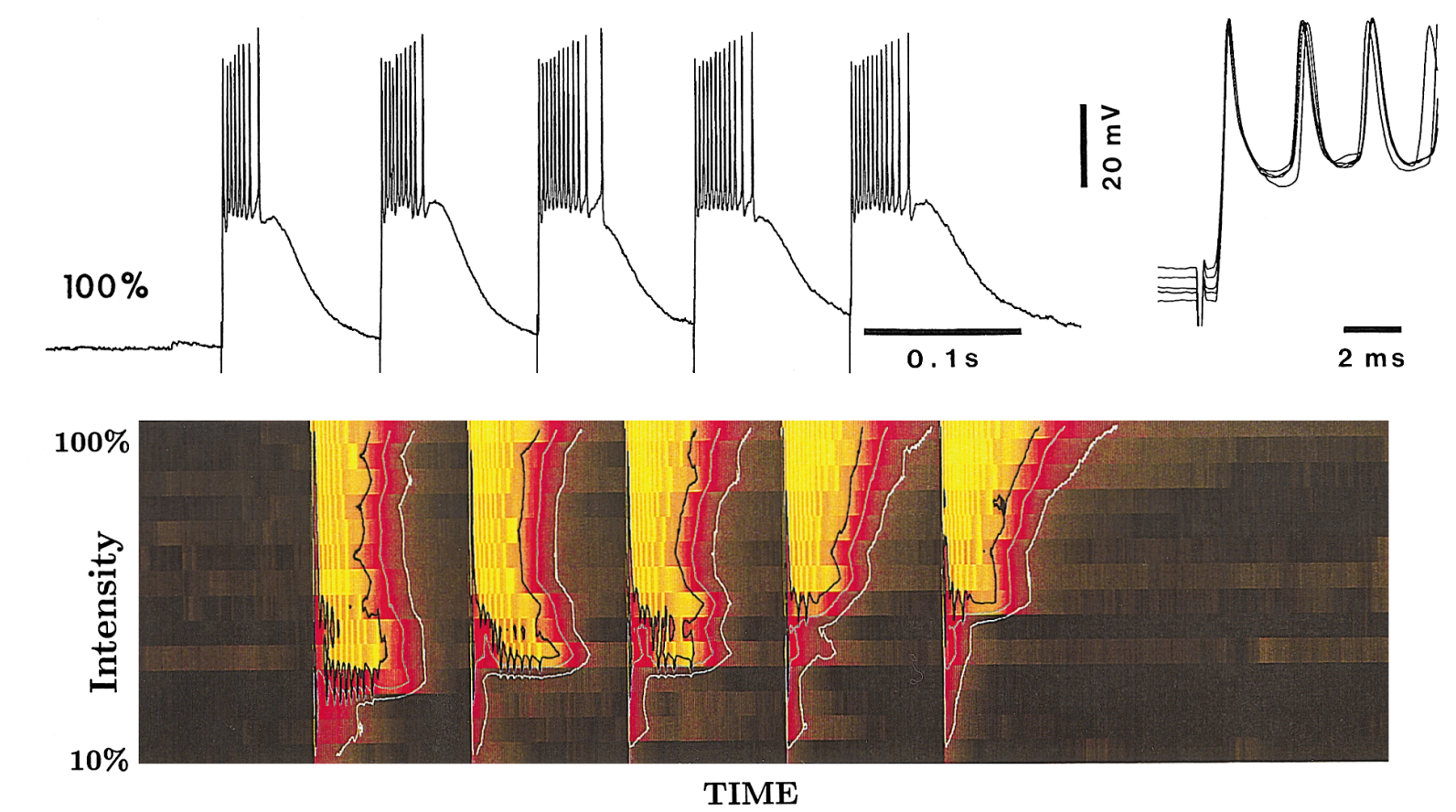

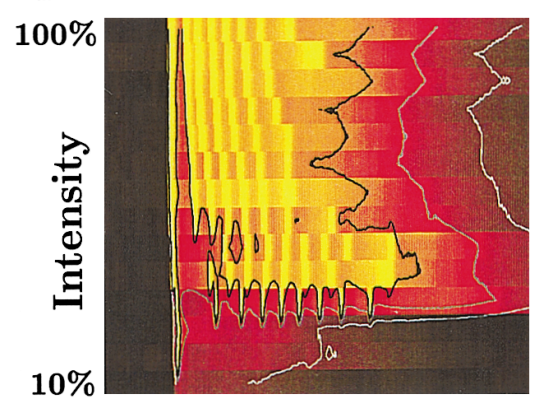

TIME
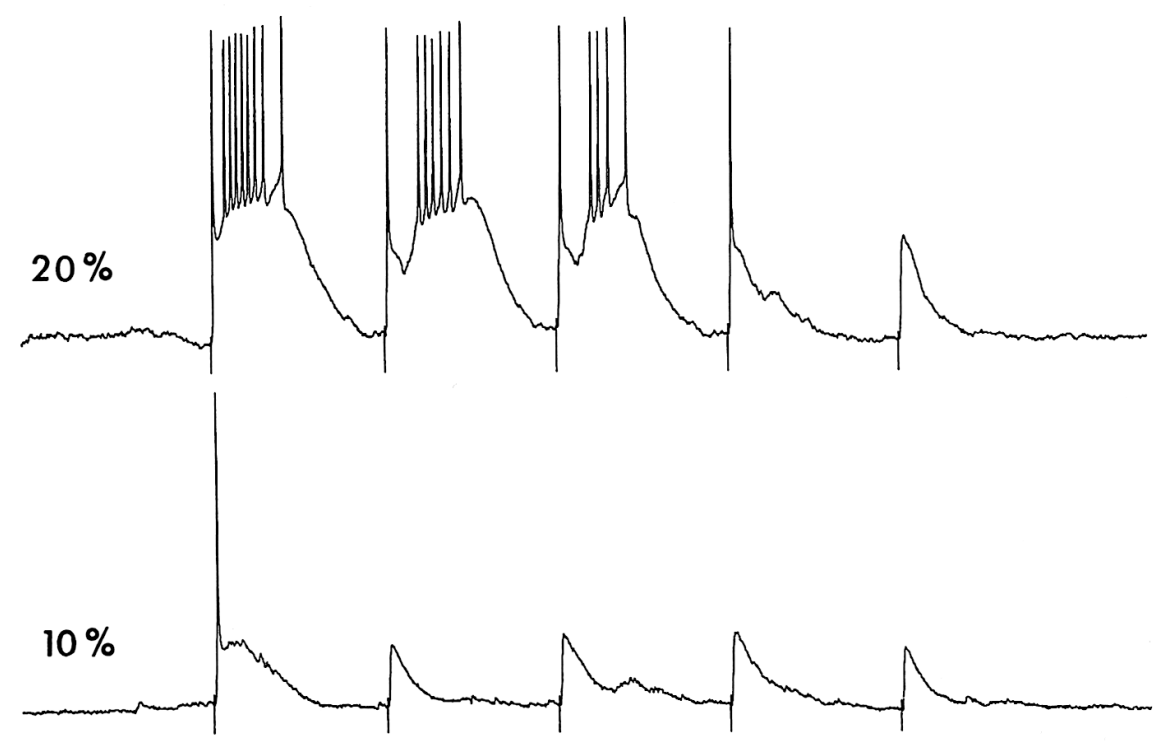

Intra-cell RE

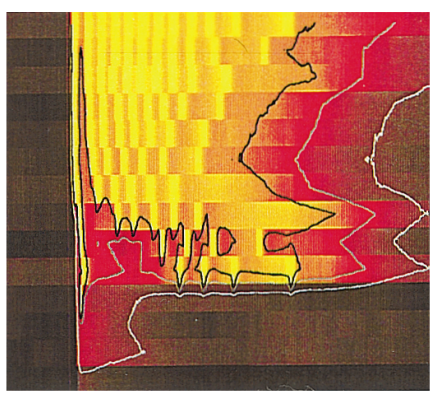

TIME

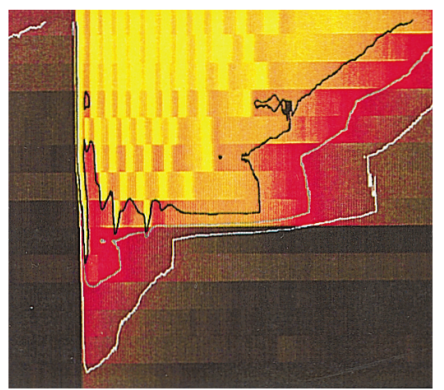

TIME
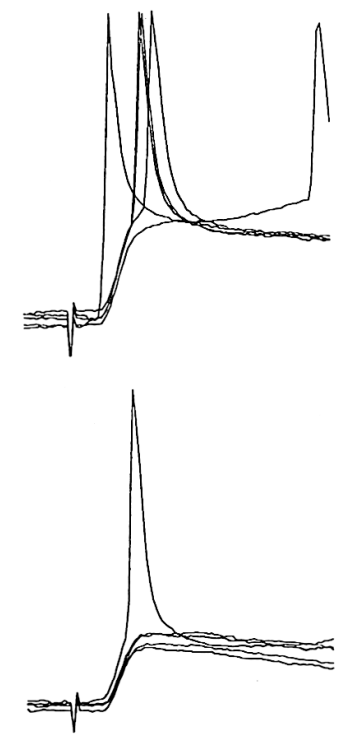
model with two pairs of RE-TC cells (Fig. $1 B$ ), a third model with two one-dimensional chains of RE and TC cells (Fig. 1C), and a fourth model that used two-dimensional networks of TC and RE cells. Typically each TC cell had an excitatory connection with its 9 ( 49 for the 2-dimensional case) nearest neighbors in the chain of RE cells and each RE cell made inhibitory synapses on the 9 (49 for the 2-dimensional case) nearest neighbors from layer of TC cells (and also inside the layer of RE cells). In some cases, we used interconnections with a wider divergence. In this case, the sum of the maximal conductances on a cell was kept fixed by rescaling the maximal conductances for individual synapses (Destexhe et al. 1994a). All connections were identical and were described by Eqs. 6-8. Reflective boundary conditions were used. Stimulation of thalamic cells was modeled by AMPA synapses that had a maximal conductance $g_{\text {ext }}=0.5 \mu \mathrm{S}$ at the center of stimulation and decayed exponentially with distance $x$ from the center $\exp (-k x)$ with $k=0.1$ (see Fig. $1 C$ ). Some of the intrinsic parameters of the neurons in the network $\left(g_{\mathrm{KL}}, g_{\mathrm{h}}\right.$ for TC cells and $g_{\mathrm{KL}}$ for RE cells) were initialized with some random variability (variance $\sigma \sim 20 \%$ for $g_{\mathrm{KL}}$ and $\sigma \sim 10 \%$ for $g_{\mathrm{h}}$ ) to diminish the effect of lateral inhibition between reticular neurons and to ensure the robustness of the results.

\section{Computational methods}

All simulations described in the paper were performed using a fourth-order Runge-Kutta [RK(4)] integration method and in some cases an embedded Runge-Kutta [RK6(5)] method (Enright et al. 1995). The time step was $0.04 \mathrm{~ms}$. Source $\mathrm{C}++$ code was compiled on a Alpha Server 2100A (5/300) using GCC compiler (version 2.7.2.2). A simulation of $1 \mathrm{~s}$ of real time for $1 \mathrm{RE}-\mathrm{TC}$ pair ( 2 cells ) took $4 \mathrm{~s}$, and for a network with 27 pairs (54 cells), it took 4.2 min. A two-dimensional network (1,458 cells) took $\sim 13.5 \mathrm{~h}$ of computer time to simulate $1 \mathrm{~s}$ of real time.

\section{In vivo recordings}

In vivo intracellular recordings were performed in the ventrolateral (VL) and lateral posterior (LP) nuclei of dorsal thalamus as well as in rostro-lateral sector of RE nucleus in adult decorticated cats anesthetized with ketamine and xylazine $(10-15 \mathrm{mg} / \mathrm{kg}$; $2-3 \mathrm{mg} / \mathrm{kg} \mathrm{im}$ ). Experimental preparation as well as the parameters of electrical stimulation and recording methods were identical to those previously described in detail (Steriade and Timofeev 1997; see also companion paper Timofeev and Steriade 1998). An array of four stimulating electrodes, separated by $1 \mathrm{~mm}$, was inserted in the thalamus to cover the territories of VL, anterior and posterior parts of the rostral intralaminar centrolateral (CLa and CLp) nucleus, and LP nucleus. To investigate the possibility of eliciting augmenting responses by stimulation of specific ascending pathways (terminating in the dorsal thalamus only), we stimulated the brachium conjunctivum rhythmically at $10 \mathrm{~Hz}$ while recording in VL.

\section{RES ULTS}

\section{Properties of intrathalamic augmenting responses in vivo}

The results reported below are based on in vivo intracellular recordings from $>400$ TC cells and 92 RE cells in unilaterally decorticated cats.
At high intensities of stimulation at $10 \mathrm{~Hz}$, responses from RE thalamic cells exhibited robust augmenting responses characterized by an increasing number of spikes and increasingly long depolarizing responses (Fig. 2). In contrast, at lower intensities of stimulation the responses to successive stimuli decremented, with a progressively decreasing number of spikes. The responses of RE cells to synaptic stimulation at low intensity revealed the coupling between the EPSP and the low-threshold spike (LTS) because of delayed LTS initiation. The efficacy of EPSP to LTS coupling is a major factor that determines whether the response is either incrementing or decrementing. At the lowest intensities of synaptic stimulation some of the EPSPs leads to the abortive LTSs while other ones do not. This becomes evident by comparison of the responses to the first shock at $10 \%$ of stimulation with responses to second to fifth stimuli at 10 and $20 \%$.

In TC cells, a single thalamic stimulus typically induced an EPSP and a biphasic IPSP followed by a rebound burst, which could lead to one or few cycles of 2- to 4-Hz delta oscillations or $8-$ to $10-\mathrm{Hz}$ spindle. During a $10-\mathrm{Hz}$ train of stimuli, the membrane potential became progressively hyperpolarized by IPSPs and the low-threshold currents became progressively deinactivated. This led to an increase in the magnitude of the LTSs and an increase in the number of fast spikes in each burst (Fig. 3).

To investigate whether or not the site of stimulation influences the augmenting responses, we recorded intracellularly in the thalamic VL nucleus while stimulating the afferent brachium conjunctivum pathway at $10 \mathrm{~Hz}$. This prethalamic stimulation did not produce an augmenting response (not shown) ( see also Timofeev et al. 1996). What is the difference between the stimulation of thalamus itself and that of specific ascending prethalamic pathways? During stimulation of ascending afferent pathways, TC cells were excited monosynaptically and RE cells were excited disynaptically. Direct electrical stimulation of the thalamus led to monosynaptic activation of both TC and RE cells, and some TC and RE cells also were excited antidromically. During intrathalamic stimulation, there was a strong gradient in the intensity of stimulation from the position of the electrode tip to distal parts of the excitatory field, while brachium conjunctivum stimuli monosynaptically activated more or less equally a small population of TC cells in a localized region of the thalamus (Rispal-Padel et al. 1987a,b). This suggests that strong activation of cells in the RE nucleus may be needed to obtain augmentation in the isolated thalamus.

\section{Augmenting responses in a reciprocal pair of RE-TC cells}

Models with a varying number of RE and TC cells and synaptic connectivity were constructed to find conditions that could reproduce the basic experimental finding reported in preceding text. The simplest network model demonstrating augmenting responses during repetitive stimulation was

FIG. 2. Incremental and decremental responses in RE cell depend on intensity of stimulation. Decorticated animal. At maximal intensity (100\%), RE cell displayed augmenting responses (top). Responses at lower intensities were decremental ( 2 bottom traces, 20 and 10\%). Note that at high intensities, of stimuli the 1st spike was antidromic, whereas at lower intensities, it was replaced by monosynaptic an excitatory postsynaptic potential (EPSP) leading to a spike. Also, at low intensities of stimulation, EPSP and low-threshold spike (LTS) could occur with some delay (responses to 2nd and 3rd stimuli at 20\%). Image plot displays the responses of a RE cell to 5 thalamic stimuli at $10 \mathrm{~Hz}$ with decreasing intensities (from top to bottom, 100 to $10 \%$ ). Dark brown is $-70 \mathrm{mV}$ and below, yellow is $-30 \mathrm{mV}$ and above. Contour plots are: white, $-60 \mathrm{mV}$; gray, $-50 \mathrm{mV}$; and black, $-40 \mathrm{mV}$. Responses to 1st, 3rd, and 5th stimuli are expanded (bottom). 
a pair of coupled RE and TC cells (see Fig. 1A). To model the effect of prethalamic stimulation of ascending afferent pathways, an external AMPA response was simulated in a TC cell, whereas the RE cell only received disynaptic input through the TC cell. The external stimulus produced a fast EPSP that evoked a sodium spike in the TC cell that in turn triggered a strong EPSP in the RE cell that elicited a burst of spikes. The feedback from the burst of spikes in the RE cell produced $\mathrm{GABA}_{\mathrm{A}}$ and $\mathrm{GABA}_{\mathrm{B}}$ IPSPs in the TC cell, which partially deinactivated the low-threshold $\mathrm{Ca}^{2+}$ currents. The subsequent EPSP evoked by the external stimulus then produced a partial low-threshold $\mathrm{Ca}^{2+}$ spike in the TC cell. Continuous stimulation progressively hyperpolarized the TC neuron due to summation of IPSPs, leading to enhancement of the low-threshold responses. The TC cell reached its maximal hyperpolarization at about the fourth to fifth stimulus (Fig. 4A). The activation of $I_{\mathrm{h}}$ slightly repolarized the TC neuron, which could decrease the level of activation of low-threshold responses. This mechanism was sufficient to produce the augmenting responses in simulating of the reciprocal pair of RE-TC cells (see also further about the role of direct RE stimulation and lateral RE-RE inhibition).

To simulate the conditions obtained during intrathalamic stimulation, we provided strong external AMPA responses

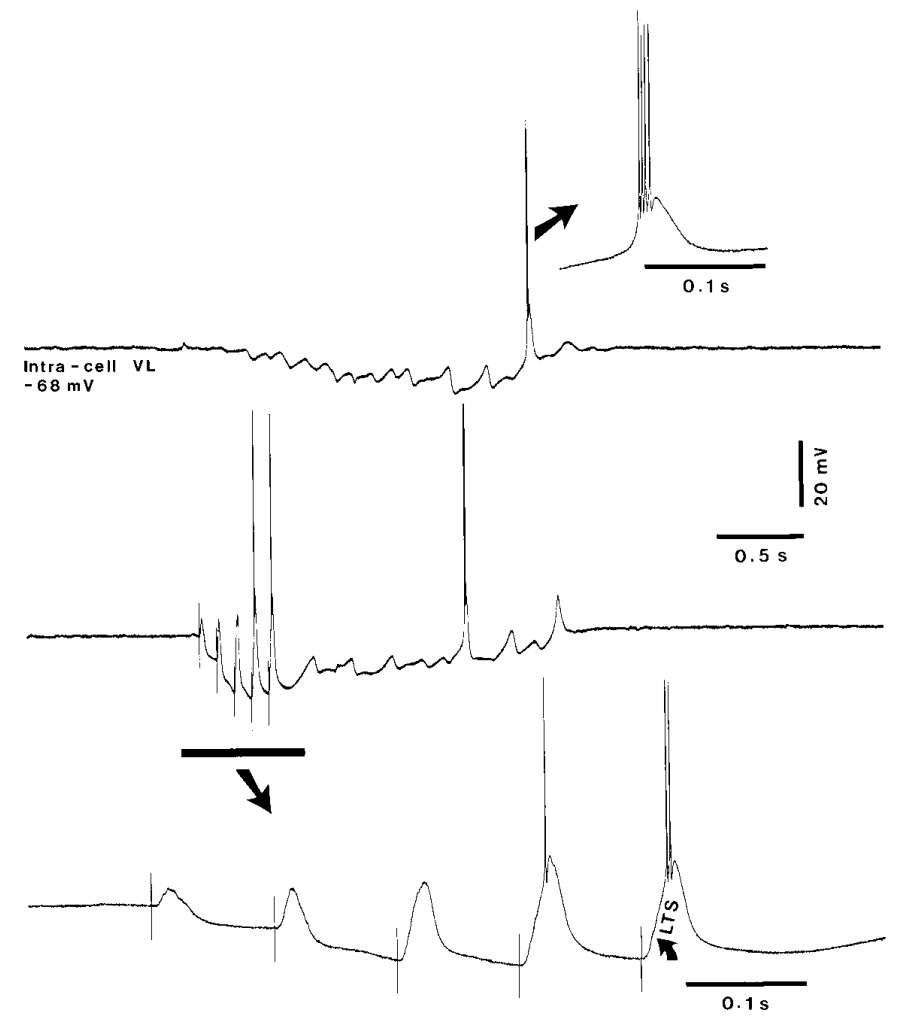

FIG. 3. Augmenting responses in ventro-lateral (VL) thalamocortical cell arising from LTSs. Decorticated animal. Top: spontaneous spindle sequence (arrow points to expanded rebound burst). Middle: 5 -shock train at $10 \mathrm{~Hz}$ produced an augmenting response stemming from hyperpolarized levels of membrane potential and followed by a spindle. Part of response indicated by horizontal bar is expanded (bottom). Progressive hyperpolarization of TC cell led to progressive growing of low-threshold responses. Oblique arrows on (bottom) indicate deflection between EPSP and LTS. Note similar shape of the LTS occurring during the spindle and evoked by stimulation. to both the TC and the RE cells. Figure $4 B$ shows the responses in the coupled RE-TC cells during repetitive stimulation of both neurons. In this case, the external stimulus produced simultaneous EPSPs in RE and TC cells that resulted in almost simultaneous burst discharges after the second stimulus in the pulse train. Prolonged bursts in the RE cell evoked stronger $\mathrm{GABA}_{\mathrm{B}}$ IPSPs and more complete deinactivation of the low-threshold $\mathrm{Ca}^{2+}$ currents in the TC cell. As a consequence, the TC responses augmented faster than when the external stimulus was applied exclusively to TC cell (compare responses to the 3rd and 4th stimuli in Fig. 4, $A 2$ and $B 2$ ).

Direct RE stimulation barely changed the strength of TC responses after the fifth stimulus in the train because in the absence of the lateral $\mathrm{GABA}_{\mathrm{A}}$ inhibition, RE cells displayed powerful burst discharges. However, there are aspects of the augmenting responses that cannot be captured by this simple RE-TC pair, and in the next section, the critical role of RE cells stimulation in a chain of coupled RE-TC cells will be explored.

Augmentation in the RE-TC pair cell model with TC cell stimulation (presented above for a $10-\mathrm{Hz}$ train of stimuli only) occurred over a range of frequencies. The highest frequency was determined by the time required for deinactivation of the low-threshold $\mathrm{Ca}^{2+}$ current in TC cell. The lowest frequency depended on the rate of TC cell repolarization: as the frequency decreased, the low-threshold $\mathrm{Ca}^{2+}$ current began to inactivate and eventually the low-threshold $\mathrm{Ca}^{2+}$ spike failed to occur. The dependence of the TC cell response on the interstimulus intervals during a train of five shocks is shown in Fig. 5.

The sequence of events that occurred between the first stimulus and the second was explored over a range of interstimulus intervals. Figure $5 A$ illustrates the responses of paired-pulse stimulation for three different interstimulus intervals. For highfrequency stimulation (interspike intervals less than $\sim 60 \mathrm{~ms}$ ), the second stimulation of the TC cell occurred when the lowthreshold $\mathrm{Ca}^{2+}$ current was still inactivated. A low-threshold $\mathrm{Ca}^{2+}$ spike was not elicited, and the response of the TC cell was not augmented. After an interstimulus interval of $140 \mathrm{~ms}$, the $I_{\mathrm{T}}$ current was almost completely deinactivated and the TC cell displayed a powerful response to the second shock. For longer interstimulus intervals, the repolarization and the rebound burst in the TC cell inactivated the low-threshold $\mathrm{Ca}^{2+}$ current, and when the second stimulus was delivered just after rebound burst (for interspike intervals between $\sim 240$ and $\sim 280 \mathrm{~ms}$ ), a nonaugmented response was evoked. For very large interstimulus intervals (greater than $\sim 280 \mathrm{~ms}$ ), the second stimulus arrived when the TC cell was hyperpolarized after the rebound burst. The hyperpolarization evoked a partial deinactivation the low-threshold $\mathrm{Ca}^{2+}$ current and the second response was augmented (see Fig. $5 B$ ).

\section{Augmenting responses in two pairs of RE-TC cells}

Figure 6 shows the responses of two coupled pairs of RE-TC cells (shown in Fig. $1 B$ ) to repetitive stimulation of both TC cells. The TC cells were identical and equally stimulated. Lateral $\mathrm{GABA}_{\mathrm{A}}$ inhibition between identical RE cells weakened the bursts in these cells, which diminished the $\mathrm{GABA}_{\mathrm{B}}$ IPSPs and delayed these augmenting responses in the TC cells (cf. Fig. $4 A$ with Fig. $6 A$ ). 
The lateral $\mathrm{GABA}_{\mathrm{A}}$ inhibition between RE cells was especially effective in reducing the total RE-evoked IPSPs in the $\mathrm{TC}$ cells when the RE cells were identical. However, even small variations in the parameters of the RE cells broke the simultaneity of the action potentials in these cells and enhanced the GABA $\mathrm{G}_{\mathrm{B}}$ IPSPs in the TC cells. Figure $6 B$ shows the responses of two coupled pairs of RE and TC cells when one of the RE cells was depolarized by $1 \mathrm{mV}$ with positive DC so that the two RE cells were not identical. For a single RE cell or two coupled identical RE cells, this depolarization would diminish burst discharges because of the partial inactivation of the low-threshold $\mathrm{Ca}^{2+}$ current. However, when the two RE cells were not identical, each of them displayed a stronger burst after every second shock. On each cycle, only one of the cells bursted strongly and the total IPSP increased more than in the case of two identical RE cells. Thus variability between RE cells resulted in a faster augmenting response in the TC cells.

\section{Augmenting responses in chains of RE-TC cells}

$\mathrm{TC}$ and RE cells are organized in an approximately topographic geometry. To study the effects of geometry on the augmenting response, we examined linear chains of $27 \mathrm{RE}$ and $27 \mathrm{TC}$ cells interacting with nine neighbors in the chain as shown in Fig. 1C. Repetitive $10-\mathrm{Hz}$ stimulation of both

\section{A1}

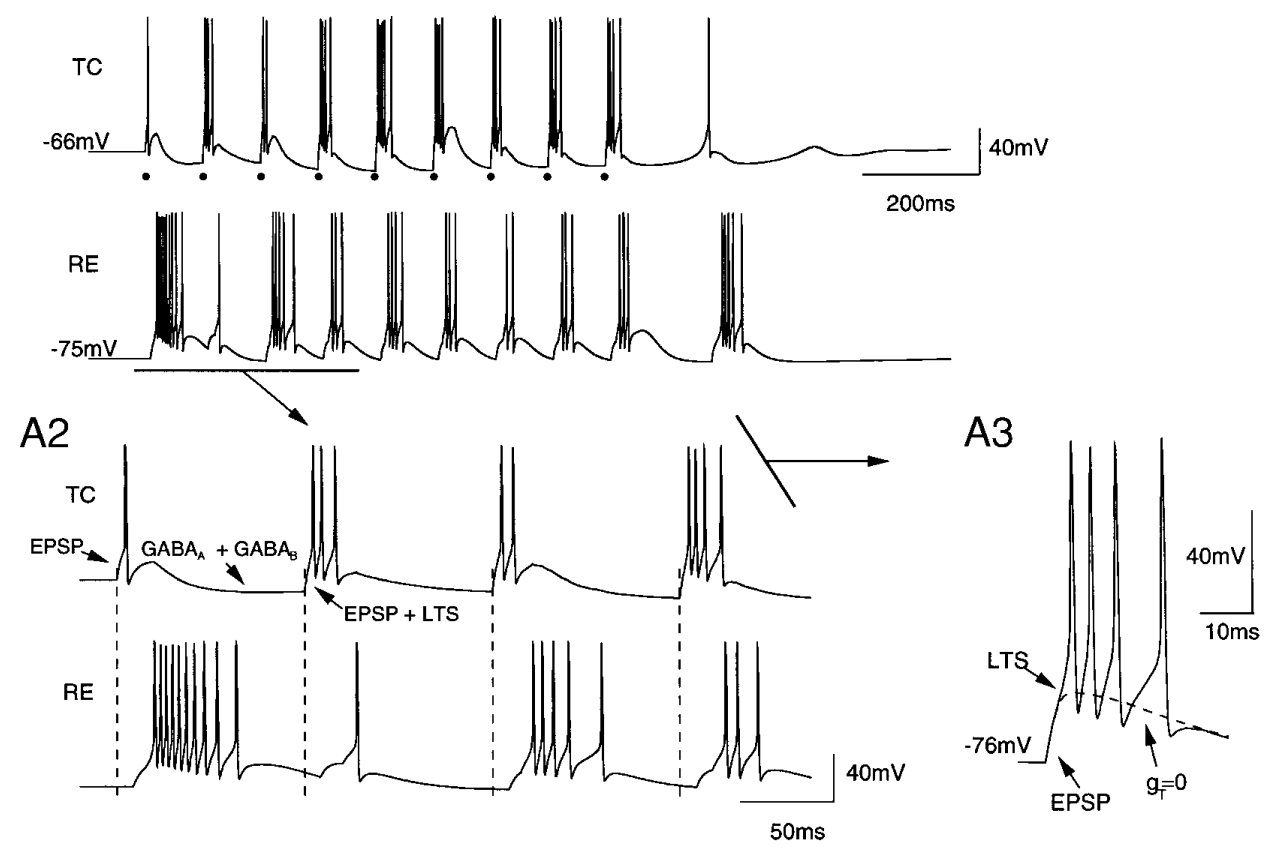

B1

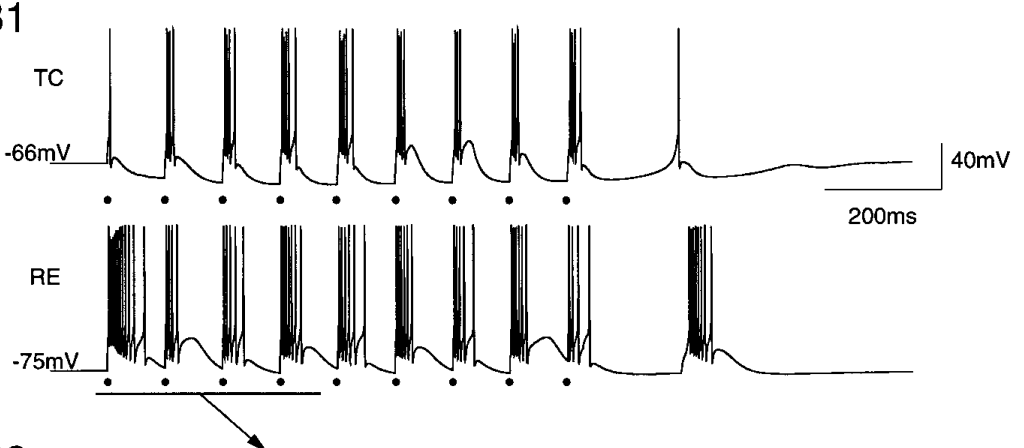

B2

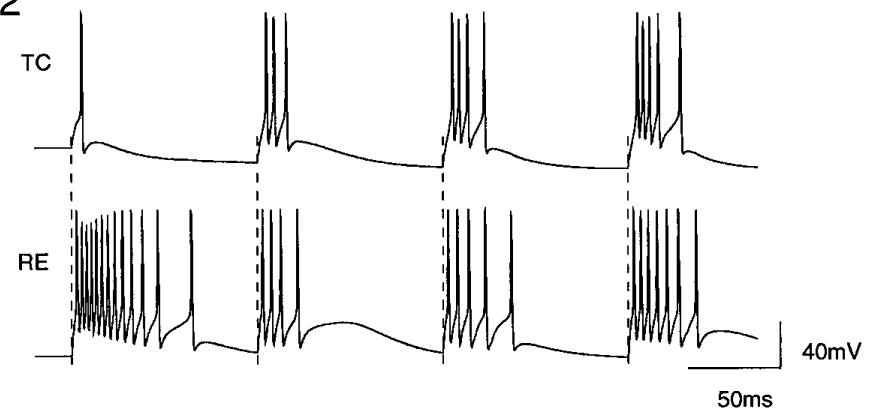

FIG. 4. Computer simulation of lowthreshold augmenting responses in a reciprocal pair of RE-TC cells. Structure of interconnections between RE and TC cells is shown in Fig. $1 A\left(g_{\mathrm{GABA}_{\wedge}(\mathrm{TC})}=0.02 \mu \mathrm{S}\right.$, $\left.g_{\mathrm{GABA}_{\mathrm{B}}}=0.05 \mu \mathrm{S}, g_{\mathrm{AMPA}}=0.07 \mu \mathrm{S}\right) . A$ : prethalamic stimulus produced an EPSP followed by the RE-induced inhibitory postsynaptic potential (IPSP) in the TC cell, which deinactivated the low-threshold $\mathrm{Ca}^{2+}$ current. Next EPSP then evoked an LTS. - - - EPSP without LTS after 4th shock $\left(A 3, I_{\mathrm{T}}\right.$ channels were blocked just before stimulation). $B$ : additional stimulation of the RE cell resulted in strong $\mathrm{GABA}_{\mathrm{B}}$ IPSPs in the TC cell and faster augmentation of the TC responses. $\bullet$, time of stimulation in $A l$ and $B 1$; vertical dashed lines, time of stimulation in $A 2$ and $B 2$. 
A
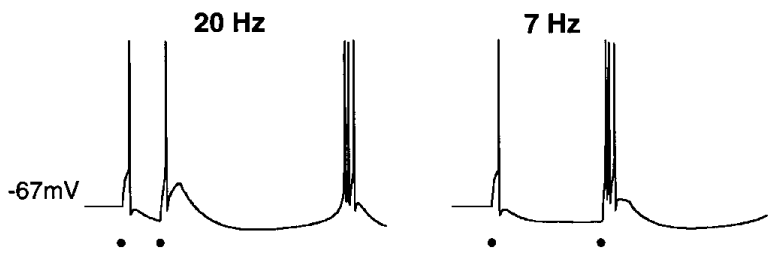

B

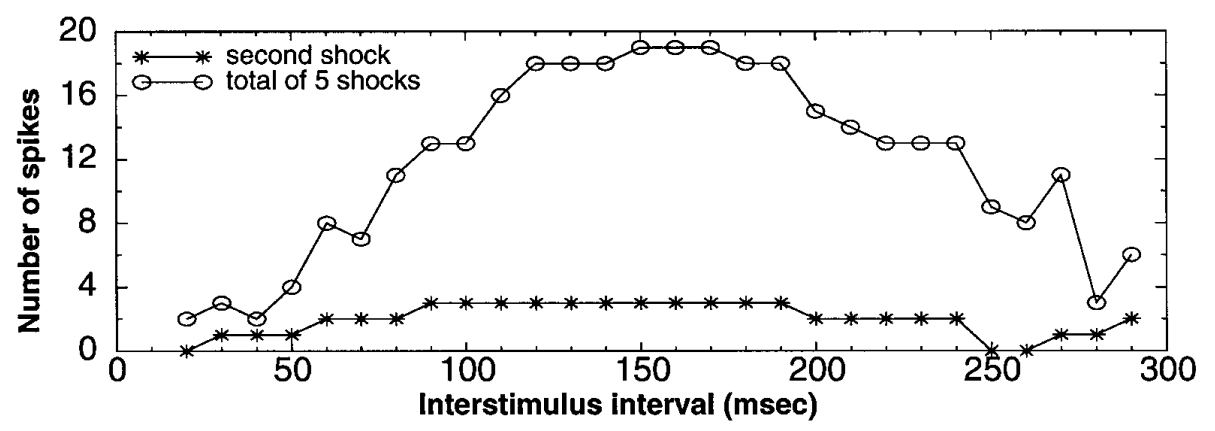

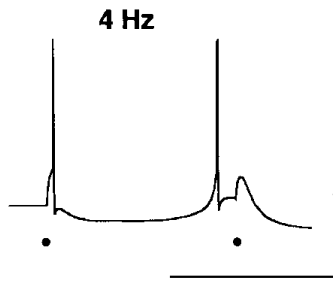
$50 \mathrm{mV}$

$200 \mathrm{~ms}$
FIG. 5. Frequency dependence of augmenting responses in a reciprocal pair of RE-TC cells shown in Fig. 1A. Both RE and TC cells were stimulated simultaneously. A: paired-pulse stimulation for different interspike intervals displayed the lack of augmentation for high $(20 \mathrm{~Hz})$ and low $(4 \mathrm{~Hz})$ stimulation frequencies. $B$ : dependence of TC responses on the interstimulus interval during train of 5 shocks. Augmenting responses were observed in the window of interstimulus intervals between $\sim 50$ and $\sim 250 \mathrm{~ms}$. the RE and the TC cells elicited incrementing activity during the first three to four stimuli in a train of 11 shocks as seen in the progressively increasing number of spikes per burst in the TC cells and by the recruitment of more TC cells that fire action potentials (Fig. 7, $A$ and $B$ ). TC cells remote from the stimulation site also participated in the augmenting response after a delay through TC-RE-TC interactions.

Figure 8 shows expanded traces of three pairs of TC and $\mathrm{RE}$ cells located at different distances from the center of stimulation. The first pair of cells (Fig. 8A) is located near the boundary of the chain and received low-intensity stimulation. This RE cell responded with a six-spike burst to the first shock and responded more weakly ( $0-2$ spikes) to the following shocks. The response decremented because the low-threshold $\mathrm{Ca}^{2+}$ current in RE cell partially inactivated during the first spike burst. If the RE cell was depolarized by current injection, so that the $I_{\mathrm{T}}$ current was completely inactivated before stimulation, then the RE cell displayed an augmenting response during the whole train of stimuli (not shown; see also Fig. 12A). The corresponding TC cell displayed a weak and delayed augmenting response with the number of spikes per burst increasing from 0 to 2 . The second pair of RE-TC cells (Fig. 8B) is closer to the center of the stimulation and received stronger stimulation. This RE cell showed a remarkable diminution of the response after the first stimulus followed by a slow augmentation of the burst. The paired TC cell displayed a strong but delayed augmentation of the responses during the train of stimuli. Finally, in the third pair of RE-TC cells (Fig. 8C) located at the center of stimulation, both of the cells (TC starting from the 1 st shock and RE starting from the 2nd shock) demonstrated strongly augmenting responses. The augmenting responses in the TC cell developed completely during the first three to four stimuli.

After the simulated train of nine shocks to the linear chain of cells, a sequence of slow delta $(3-4 \mathrm{~Hz})$ oscillations was elicited by interactions between RE and TC cells. These oscillations terminated as a result of desynchronization in the network and depolarization of TC cells, which resulted from the $\mathrm{Ca}^{2+}$ regulation of $I_{\mathrm{h}}$ current (Destexhe et al. 1996a). The duration of the poststimulus oscillations depended on the position of the cell in the chain. TC cells located far from the center of stimulation and displaying weak burst discharges were involved in the most prolonged poststimulus oscillations. In contrast, TC cells placed at the center of the chain displayed powerful burst discharges. As a consequence, the intracellular $\mathrm{Ca}^{2+}$ concentration increased rapidly during train of stimuli, and poststimulus oscillations in these TC cells were terminated after one to two cycles.

Another mechanism for terminating the poststimulus oscillations - desynchronization of the network - depends on parameter variability, the spatial extent of the external stimulation and the radii of connections between TC and RE cells. Three parameters $-g_{\mathrm{KL}}, g_{\mathrm{h}}$ for TC, and $g_{\mathrm{KL}}$ for RE cellswere varied (see METHODS). The variability in the potassium leak current (variance $\sim 20 \%$ ) produced variability in the resting membrane potentials of RE and TC cells (variance $\sim 3 \mathrm{mV}$ ), which led to slightly different inactivation of the $\mathrm{Ca}^{2+}$ currents in these cells at rest. The variability of the third parameter-maximal conductance of $I_{\mathrm{h}}$ current in TC cells (variance $\sim 10 \%$ ) - made the latencies of repolarization in TC cells different after RE-evoked hyperpolarization, which resulted in asynchronous bursts of TC cells and reduced TC-evoked EPSPs in RE cells during poststimulus oscillations. Increasing the spatial spread of connections decreased the contribution of the individual cells to the whole PSP ( see METHODS) and a higher degree of network synchronization was required to elicit augmenting responses. Figure $7 C$ shows the responses of the RE-TC cells in the linear chain with the radius of connections between RE-TC cells twice the size of the network presented in Fig. 7, $A$ and $B$. The extent of the lateral connections between RE cells projections in vivo is less than that of the RE-TC projections (Cox et al. 1996). Therefore the smaller set of connections was used between the RE cells. Increasing the extent of the connections between RE-TC cells did not change the 
character of augmentation in the TC cells and its main effect was to hasten the termination of poststimulus oscillations.

\section{Effect of RE cells stimulation}

In the model for a pair of coupled RE-TC cells, the external stimulation of RE cells increased low-threshold augmenting responses by reinforcing $\mathrm{GABA}_{\mathrm{B}}$ IPSPs in TC cells. The responses of the RE-TC network were compared when only the TC cells were stimulated (Fig. 9A) and when there was simultaneous RE-TC stimulation (Fig. 9B). The additional stimulation of RE cells produced stronger burst discharges in the RE cells, which occurred almost simultaneously with EPSPs in TC cells. The result of the earlier REevoked $\mathrm{GABA}_{\mathrm{A}}$ IPSPs was an absence of the action after first stimulus in the TC cells located far from the center of the network. But more powerful burst discharges in the RE cells elicited stronger activation of $\mathrm{GABA}_{\mathrm{B}}$ receptors and more complete deinactivation of the low-threshold $\mathrm{Ca}^{2+}$ current in TC cells. This resulted in faster augmentation of TC responses starting with the second stimulus.

In in vivo experiments with $10-\mathrm{Hz}$ stimulation of afferent
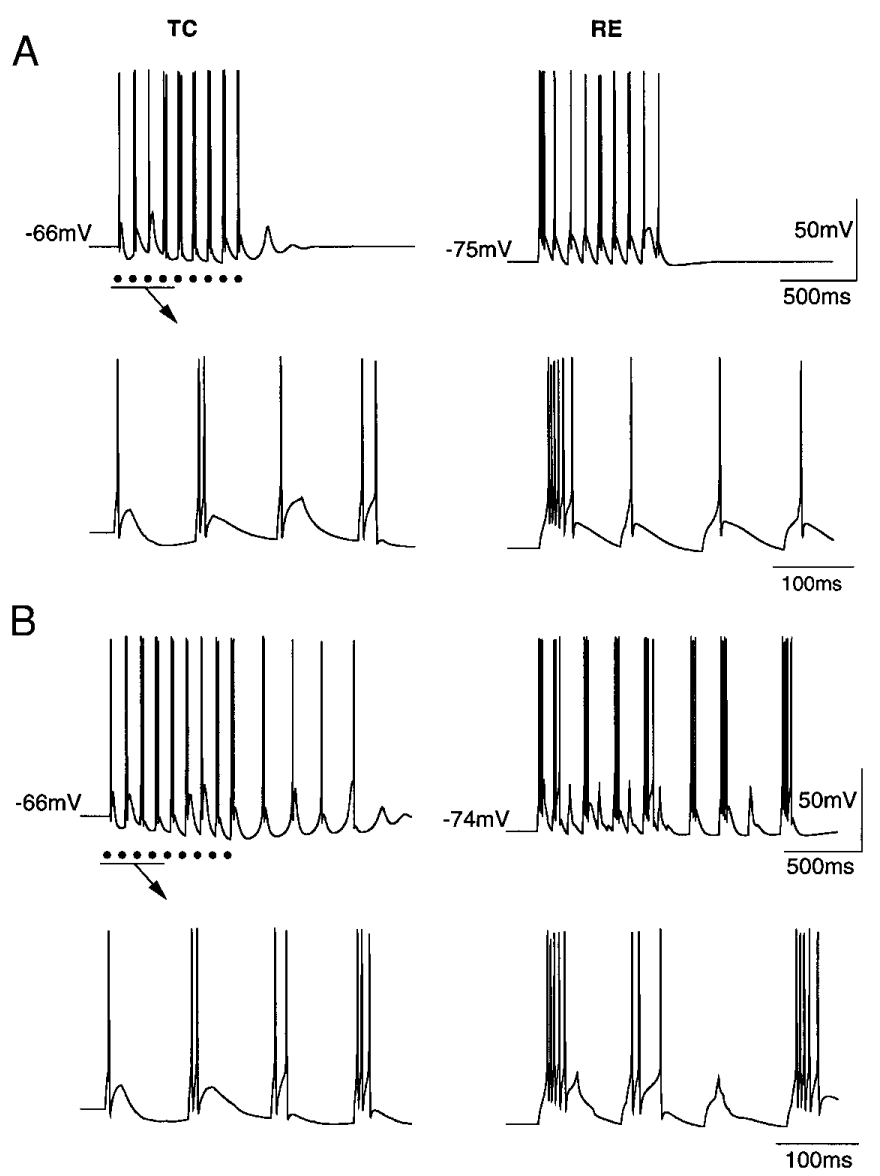

FIG. 6. Augmenting responses in 2 coupled pairs of RE-TC cells during exclusive TC stimulation. Role of lateral inhibition. Structure of interconnections between RE and TC cells is shown in Fig. $1 B\left(g_{\mathrm{GABA}_{\mathrm{A}}(\mathrm{RE})}=0.09\right.$ $\left.\mu \mathrm{S}, g_{\mathrm{GABA}_{\mathrm{A}}(\mathrm{TC})}=0.02 \mu \mathrm{S}, g_{\mathrm{GABA}_{\mathrm{B}}}=0.05 \mu \mathrm{S}, g_{\mathrm{AMPA}}=0.07 \mu \mathrm{S}\right)$. A : lateral $\mathrm{GABA}_{\mathrm{A}}$ inhibition between identical RE cells, which weakened bursts in these cells, diminished $\mathrm{GABA}_{\mathrm{B}}$ IPSPs and delayed the augmenting response in TC cells. $B$ : depolarization of $1 \mathrm{RE}$ cell by only $1 \mathrm{mV}$ destroyed the synchronization of RE cells and decreased the effect of lateral $\mathrm{GABA}_{\mathrm{A}}$ inhibition that resulted in faster augmenting responses in the TC cells. $\bullet$, time of stimulation. brachium conjunctivum pathway the TC cells from the VL nucleus displayed monosynaptic responses, occasionally leading to fast spikes, but without augmentation (not shown). In the experiments with prethalamic stimulation of ascending afferent pathways, only the excitatory synapses of TC cells were partially activated, which resulted in a weak and quasihomogeneous stimulation of TC cells and an absence of external input to RE cells. Figure 10 shows the responses of a selected TC cell from the network during exclusive TC stimulation (Fig. 10A) and for simultaneous RE-TC stimulation (Fig. 10B). In both cases, the intensity of stimulation decayed slowly throughout the network with a ratio $k=0.02$ (that is 5 times smaller than in the previous experiments). Figure $10, A l$ and $B l$, shows TC responses for low-intensity stimulation. In the absence of RE stimulation, the TC cell displayed single spike responses without augmentation during the entire train of stimuli. However, additional RE stimulation reinforced RE-evoked $\mathrm{GABA}_{B}$ IPSPs and produced augmenting responses in the TC cells. For moderate intensity of the input, the additional RE stimulation resulted in strong and rapid augmentation of TC cell responses (from 1 to $4-5$ spikes), whereas exclusive TC stimulation led to much weaker (from 1 to 2-3 spikes) augmenting responses (Fig. 10, $A 2$ and $B 2$ ). Finally, for high-intensity stimulation, strong monosynaptic activation resulted in powerful burst-discharges in TC cells starting from beginning of the pulse train (Fig. 10, $A 3$ and $B 3$ ).

Thus the additional stimulation of RE neurons is a necessary condition for augmentation to occur in response to moderate and low-intensity stimulation. Note that the boundary cells in the experiment presented in Fig. 9 displayed weak augmenting responses (from 0 to 1 spike) in spite of the low-intensity stimulation. In this case (in contrast to the experiment with quasihomogeneous stimulation shown in Fig. 10), the central RE cells displayed strong burst discharges that led to GABA $\mathrm{B}_{\mathrm{B}}$ IPSPs in the boundary TC cells through lateral RE-RE and RE-TC connections.

\section{Role of DC and stimulation intensity}

Thalamic augmentation based on the deinactivation of the low-threshold $\mathrm{Ca}^{2+}$ spikes is only effective for some range of membrane potentials. When the thalamic relay cells were sufficiently hyperpolarized or depolarized, the TC cells displayed nonaugmented responses during the entire train of stimuli.

Figure $11 \mathrm{~A}$ shows the responses of one of TC cells depolarized by direct current. The DC prevented deinactivation of the low-threshold current, and the TC cell did not display augmentation of the responses as observed for $\mathrm{DC}=0$ (compare Fig. 11, $A$ with $B$ ). Progressive RE-evoked hyperpolarization of the TC cell during a train of stimuli resulted in the abolition of the spontaneous firing observed before stimulation.

Figure $11 C$ shows the same TC cell under negative DC. Strong hyperpolarization resulted in the complete deinactivation of the low-threshold current before stimulation. Therefore the first shock already evoked a powerful response. The partial inactivation of $I_{\mathrm{T}}$ current during stimulus-evoked burst discharges led to the weakening of the responses to the subsequent stimuli.

In the RE-TC simulations, a strong $\mathrm{GABA}_{\mathrm{B}}$ component 
A
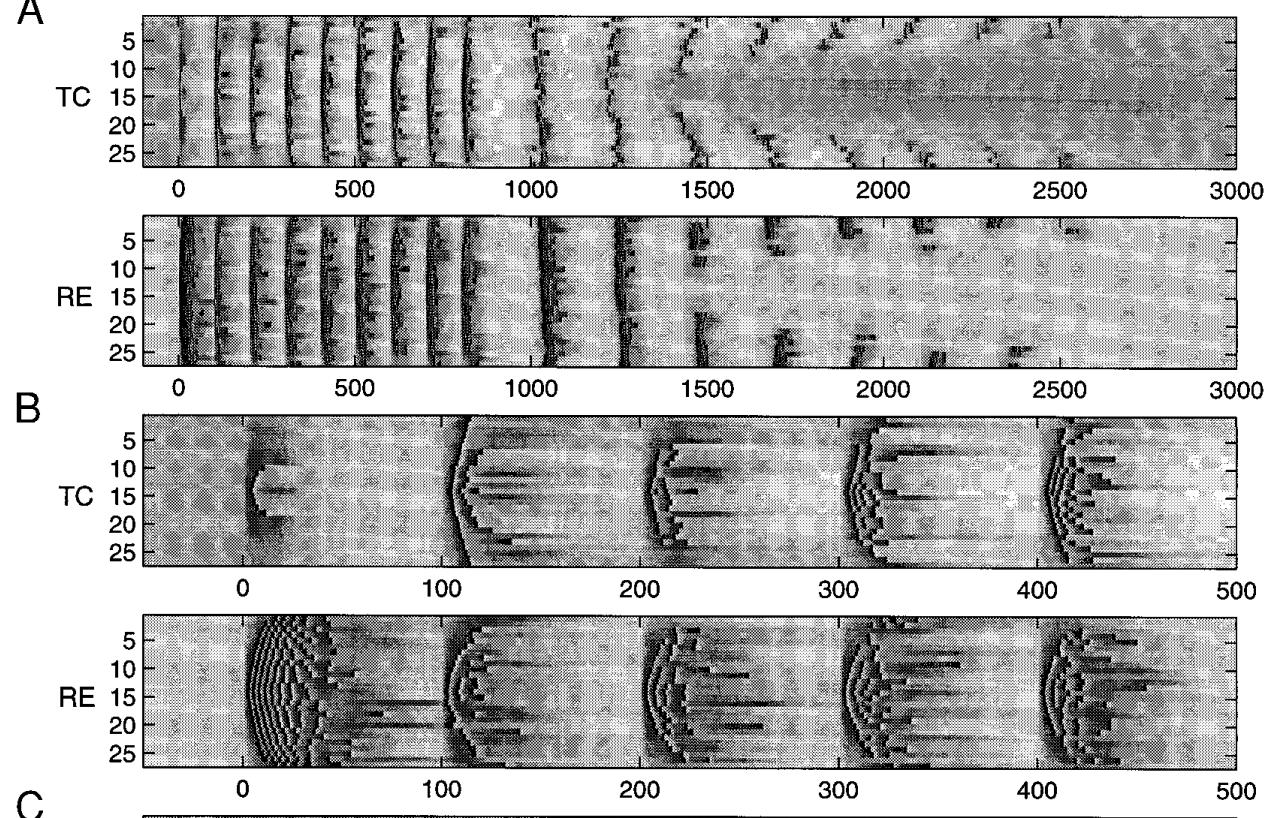

C
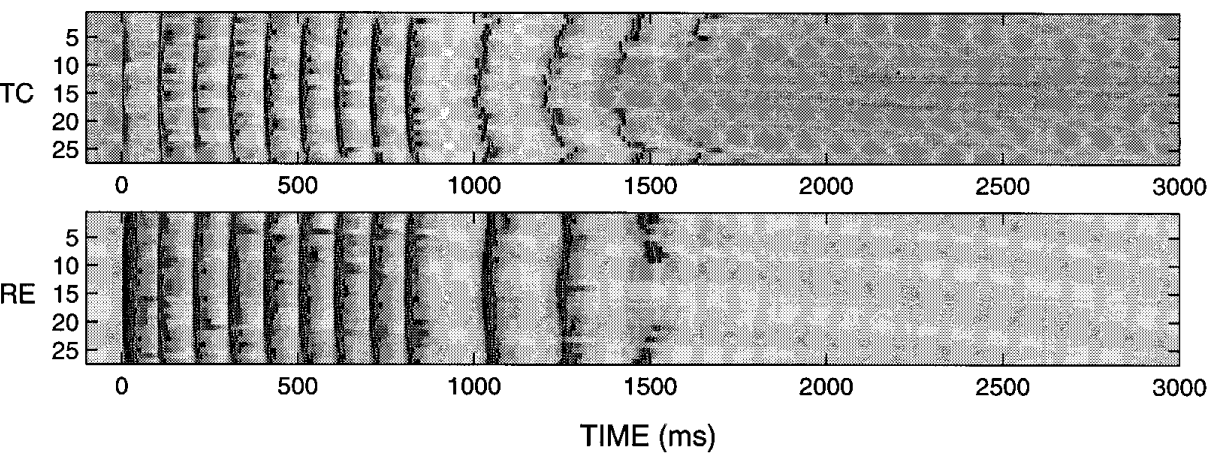

FIG. 7. Augmenting responses of 27 TC and $27 \mathrm{RE}$ cells during $10 \mathrm{~Hz}$ stimulation in the chain of interacting RE and TC cells. Structure of interconnections between $\mathrm{RE}$ and TC cells is shown in Fig. 1C $\left(g_{\mathrm{GABA}_{\star}(\mathrm{RE})}=0.07 \mu \mathrm{S}, g_{\mathrm{GABA}_{\star}(\mathrm{TC})}=0.02\right.$ $\left.\mu \mathrm{S}, g_{\mathrm{GABA}_{\mathrm{B}}}=0.07 \mu \mathrm{S}, g_{\mathrm{AMPA}}=0.07 \mu \mathrm{S}\right)$. Nine shocks were applied between $t=0$ $\mathrm{ms}$ and $t=800 \mathrm{~ms}$. Both RE and TC cells were stimulated simultaneously. Intensity of stimulation was maximal in the center of the chain and decayed exponentially with distance from the center. $A$ and $B$ : diameter of connections for all projections was 9 cells. Expanded traces of $A$ between $t=$ $-50 \mathrm{~ms}$ and $t=500 \mathrm{~ms}$ are given in $B$. First 4 shocks in the train of 9 shocks evoked incremental responses in the TC cells. RE cells demonstrated a diminished response to the 2nd shock because of the partial inactivation of low-threshold current in these cells and increasing of the responses to the following shocks. Train of stimuli was followed by slow $4-5-\mathrm{Hz}$ poststimulus oscillations. $C$ : diameter of connections for RE-TC, TC-RE projections was 17 cells. Smaller diameter of connections ( 9 cells) was used for RE-RE projections. Increasing the radius of RE-TC connections decreased the contribution of the individual cells to the whole postsynaptic potential. That resulted in the faster desynchronization of the network after train of stimuli and termination of poststimulus oscillations. Value of membrane potential for each neuron is coded in grey scale from $-90 \mathrm{mV}$ (white) to $-30 \mathrm{mV}$ (black).

in the RE-evoked IPSPs is a necessary condition for deinactivation of $I_{\mathrm{T}}$ current in TC cells during repetitive stimulation. The kinetic scheme activated by the $\mathrm{GABA}_{\mathrm{B}}$ receptors involving $G$ proteins requires prolonged burst discharges in the RE cells to elicit powerful GABA ${ }_{B}$ IPSPs, and the bursts depend on the low-threshold $\mathrm{Ca}^{2+}$ current. Strong depolarization of RE cell by positive DC current injection inactivated the $I_{\mathrm{T}}$ current, and the RE cell responded only weakly during a train of stimuli (not shown). At smaller depolarizing DC levels, an RE cell displayed augmenting responses (Fig. 12A). In this case, augmentation was obtained as a result of augmenting responses in TC cells. In the absence of DC current injection, the same RE cell displayed a powerful burst discharge for the first stimulus and decrementing responses for subsequent stimuli (Fig. 12B). The diminution of the burst discharges in the RE cell despite increasing EPSPs can be explained by the partial inactivation of the low-threshold current in this cell.

We next explored the effect of changing the strength of stimulation in the absence of a DC current injection. For low-intensity stimulation (Fig. 12C), the RE cell displayed an EPSP and a delayed burst discharge only for the first shock and responded with EPSPs without action potentials for subsequent stimuli. The explanation for this "passive" response already has been given - the low-threshold $\mathrm{Ca}^{2+}$ current was inactivated partially during the first burst and repetitive EPSPs further prevented its deinactivation. For high-intensity stimulation (Fig. 12D), RE cells responded with a more powerful burst discharge for the first stimulus but subsequent stimuli evoked similar responses without augmentation.

\section{Augmenting responses in the isolated RE nucleus}

Because augmenting responses mimic spindle oscillations and spindles can be generated in the isolated RE nucleus in vivo (Steriade et al. 1987), we asked whether or not augmenting responses can be elicited in isolated RE neurons and, if so, what are the underlying mechanisms of such responses? Intra-RE synaptic connections include both $\mathrm{GABA}_{\mathrm{A}}$ and $\mathrm{GABA}_{\mathrm{B}}$ components. However, the $\mathrm{GABA}_{\mathrm{B}}$ component for RE-RE coupling is weaker than for RE-TC projection (Sanchez-Vives et al. 1997; Ulrich and Huguenard 1996). Here we analyze the effect of weak intrareticular $\mathrm{GABA}_{\mathrm{B}}$ synaptic coupling during repetitive stimulation of the isolated RE nucleus.

The response of an RE cell in a pair of coupled RE cells during repetitive stimulation was studied in the case of pure $\mathrm{GABA}_{\mathrm{A}}$ coupling between cells and for mixed $\mathrm{GABA}_{\mathrm{A}^{-}}$ $\mathrm{GABA}_{\mathrm{B}}$ synapses (Fig. 13A). A weak $\mathrm{GABA}_{\mathrm{B}}$ component (maximal conductance was only $\sim 25 \%$ of the maximal conductance of RE-TC GABA $_{B}$ coupling) resulted in a slow hyperpolarization of the RE cells during a train of stimuli; this led to the deinactivation of the low-threshold $\mathrm{Ca}^{2+}$ cur- 
A

TC

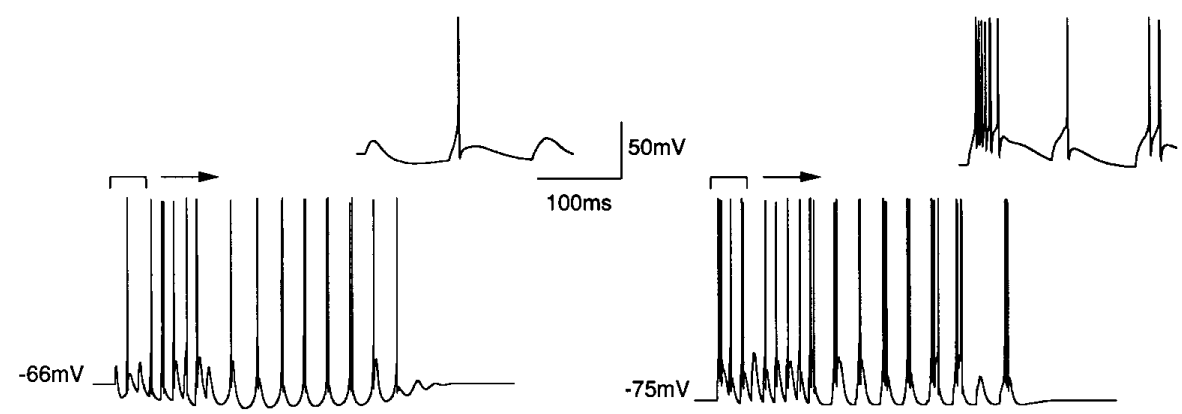

B

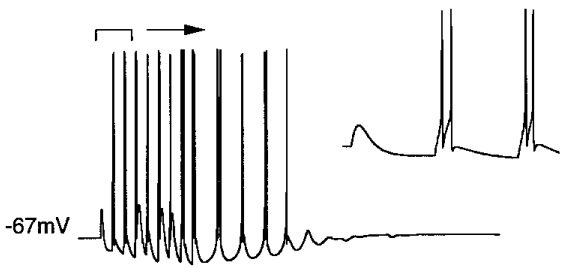

C

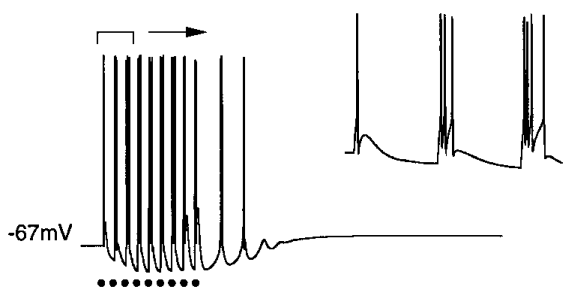

RE
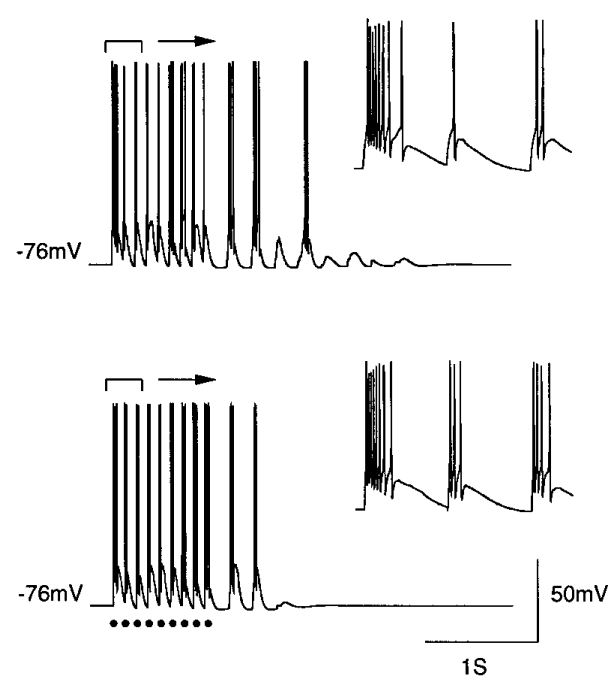

FIG. 8. Expanded traces of three TC cells from a chain of RE-TC cells presented in Fig. 7. Insets: responses to the first 3 stimuli at a different time scale. $A$ : TC cell placed far from the center of the chain (cell 3 ) obtained a low-intensity stimulation that resulted in a weak and delayed augmenting response followed by prolonged 3- to 5$\mathrm{Hz}$ oscillations. Related RE cell showed a strong response to the 1 st shocks and very weak responses to subsequent shocks. Poststimulus oscillations were terminated as a result of desynchronization in the network caused by variability in the parameters of the cells. $B$ : TC cell placed closely to the center of the stimulation (cell 7) showed stronger augmentation of the responses and faster termination of the poststimulus oscillations. $C$ : TC cells placed near the center of stimulation (cell 14) showed a fast augmenting responses and just a few cycles of slow poststimulus oscillations. RE cell displayed a diminished response to the 2nd shock and augmentation of the responses to the following shocks.
A
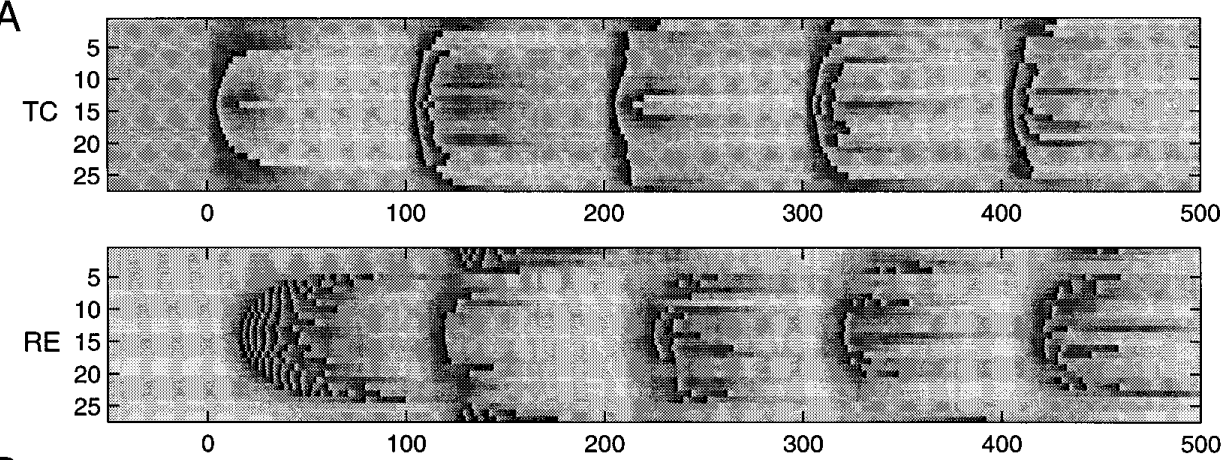

B
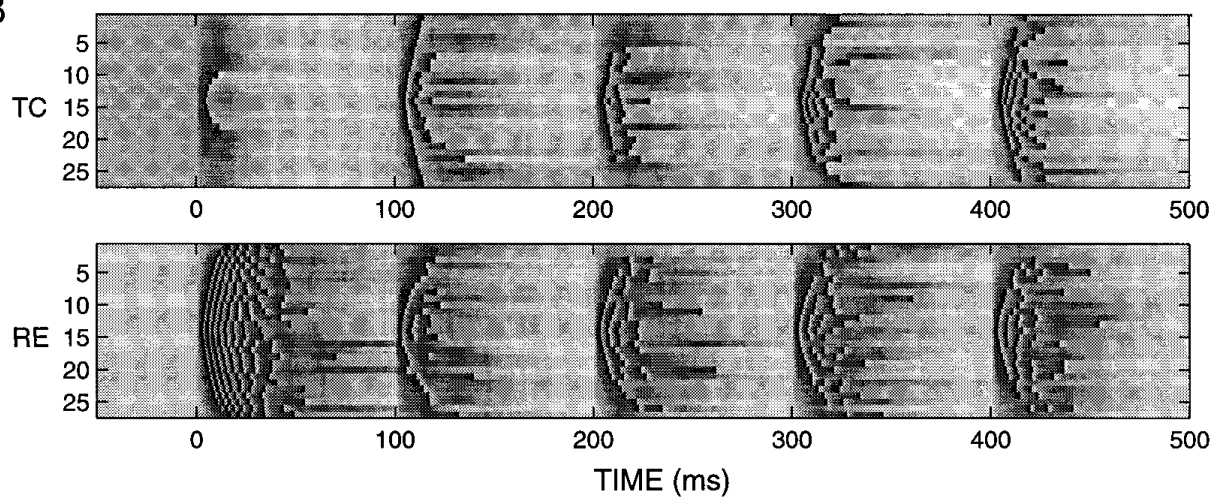

FIG. 9. Role of additional RE stimulation for augmenting responses. Chain of $27 \mathrm{TC}$ and $27 \mathrm{RE}$ cells is shown during $10 \mathrm{~Hz}$ stimulation $\left(g_{\mathrm{GABA}_{\mathrm{A}}(\mathrm{RE})}=0.07 \mu \mathrm{S}, g_{\mathrm{GABA}_{\mathrm{A}}(\mathrm{TC})}=\right.$ $0.02 \mu \mathrm{S}, g_{\mathrm{GABA}_{\mathrm{B}}}=0.07 \mu \mathrm{S}, g_{\mathrm{AMPA}}=0.07$ $\mu \mathrm{S}) . A$ : only TC cells were stimulated. $B$ : both TC and RE cells were stimulated. In the latter case, RE cells displayed much stronger burst discharges occurring simultaneously with TC cells' depolarization, which evoked earlier and stronger $\mathrm{GABA}_{\mathrm{A}}-\mathrm{GABA}_{\mathrm{B}}$ IPSPs in the TC cells. Earlier $\mathrm{GABA}_{\mathrm{A}}$ component of IPSP decreased the responses of the TC cells after 1st stimulus. However, the powerful $\mathrm{GABA}_{\mathrm{B}}$ IPSPs increased hyperpolarization of the TC cells and led to greater deinactivation of the low-threshold $\mathrm{Ca}^{2+}$ current. This resulted in larger LTSs and longer burst discharges in the TC cells. Membrane potential for each neuron is coded in grey scale from $-90 \mathrm{mV}$ (white) to $-30 \mathrm{mV}$ (black). 

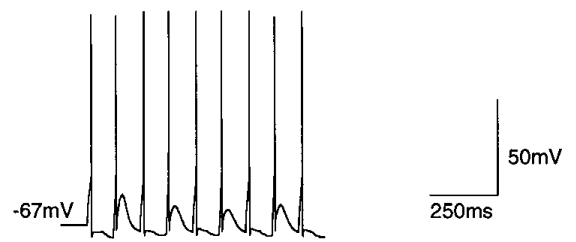

$\mathrm{A} 2$

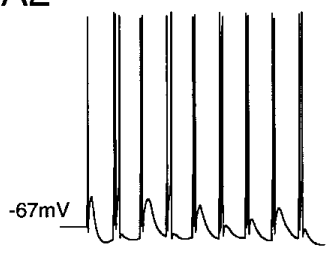

A3

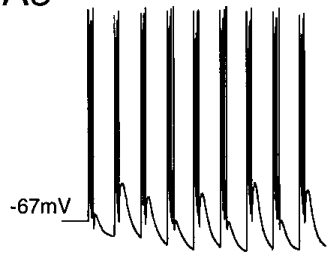

B1

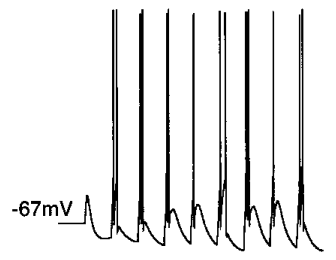

B2
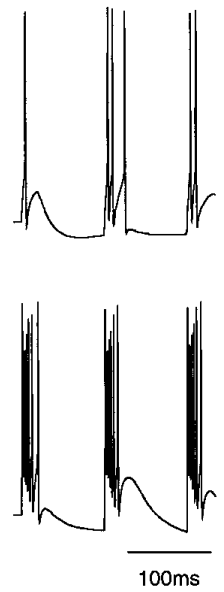

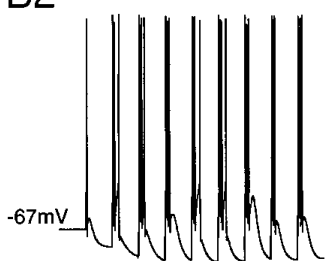

B3

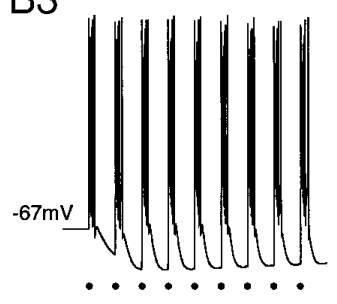

FIG. 10. Comparison of responses evoked by prethalamic and thalamic stimulation. Expanded traces of 1 TC cell from a chain of 27 cells are shown for different intensities of stimulation. Intensity of stimulation decayed exponentially with distance from the center with a small ratio $k=0.02\left(g_{\mathrm{GABA}_{\mathrm{A}}(\mathrm{RE})}=0.07\right.$ $\mu \mathrm{S}, g_{\mathrm{GABA}_{\mathrm{A}}(\mathrm{TC})}=0.02 \mu \mathrm{S}, g_{\mathrm{GABA}_{\mathrm{B}}}=0.07 \mu \mathrm{S}$, $\left.g_{\mathrm{AMPA}}=0.07 \mu \mathrm{S}\right)$. Responses to the first 3 stimuli are expanded at right (2nd and 4th columns) with different time scale. $A$ : only TC cells were stimulated. $B$ : both TC and RE cells were stimulated. With low-intensity input (see $A l$ and $B l$ ), dual (RE and TC cells) stimulation was a necessary condition for developing augmenting responses. Stimulation of TC cells alone elicited single spike responses without augmentation. For moderate intensities of stimulation ( see $A 2$ and $B 2$ ), exclusive TC stimulation resulted in a weak augmentation of TC responses only. In contrast, dual RE-TC stimulation led to strong hyperpolarization of TC cells and greater augmenting responses. In the case of high-intensity stimulation (see $A 3$ and $B 3$ ), TC cells demonstrated strong (nonaugmented) responses from onset of stimulation. Dual stimulation eliminated time delays between EPSPs in RE and TC cells and all cells were almost simultaneously depolarized. rent and an augmenting responses of RE cells. The augmentation was absent if the RE-RE GABA $_{B}$ receptors were blocked.

Figure $13 B$ shows the responses of $27 \mathrm{RE}$ cells with mixed $\mathrm{GABA}_{\mathrm{A}}-\mathrm{GABA}_{\mathrm{B}}$ coupling during repetitive stimulation. The same set of local intra-RE connections were used as before (see earlier text, Fig. 1C). The RE cells located near the center of network displayed slowly augmenting responses (from 2-3 to 4 spikes) during a train of stimuli. In contrast, the neurons near the boundary of the network that received weak stimulation displayed short burst discharges without significant augmentation. Thus the augmenting responses in the isolated RE nucleus demonstrated the same features found in TC cells. The results of these simulations indicate that the low-threshold mechanism for augmentation is not limited to TC cells. In the presence of lateral $\mathrm{GABA}_{\mathrm{B}}$ inhibition responsible for deinactivation of the low-threshold $\mathrm{Ca}^{2+}$ current, the RE network displayed an augmenting response during repetitive stimulation.

\section{Synaptic conductances}

In the preceding simulations, deinactivation of the lowthreshold $\mathrm{Ca}^{2+}$ current underlies the augmenting response

A

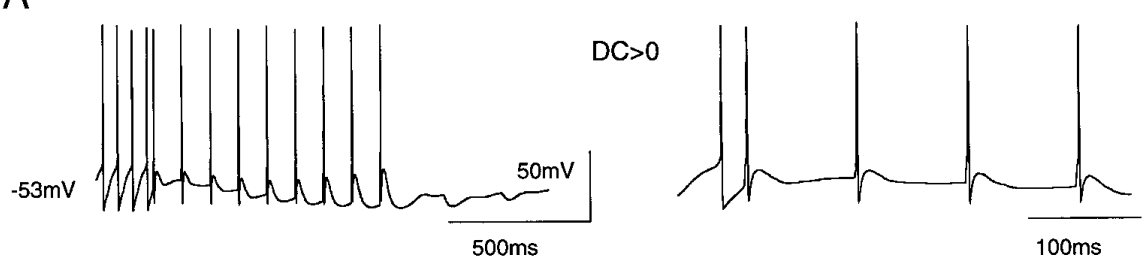

B

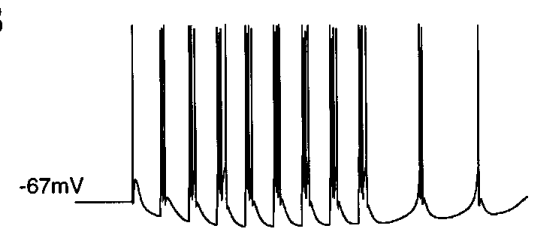

$\mathrm{DC}=0$

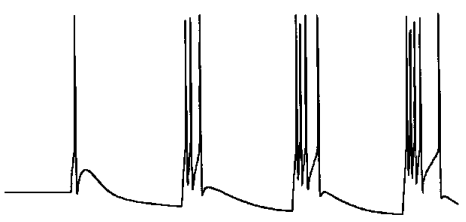

C

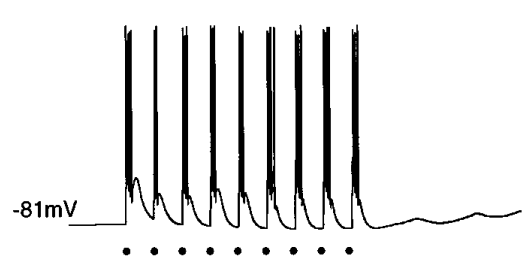

$\mathrm{DC}<0$

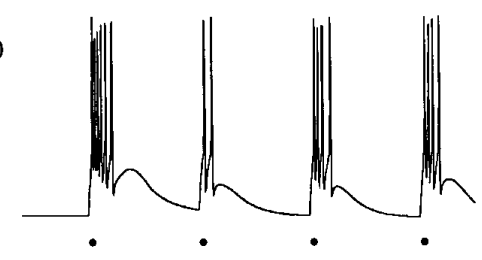

FIG. 11. Role of membrane potential in augmenting responses of TC cells. One TC cell from a chain of RE-TC cells is shown at different levels of DC current during train of stimuli at $10 \mathrm{~Hz}$ $\left(g_{\mathrm{GABA}_{\mathrm{A}}(\mathrm{RE})}=0.07 \mu \mathrm{S}, g_{\mathrm{GABA}_{\mathrm{A}}(\mathrm{TC})}=0.02 \mu \mathrm{S}\right.$, $\left.g_{\mathrm{GABA}_{\mathrm{B}}}=0.07 \mu \mathrm{S}, g_{\mathrm{AMPA}}=0.07 \mu \mathrm{S}\right)$. Responses to the first four stimuli are expanded at right. Augmentation observed for $\mathrm{DC}=0$ was abolished during both depolarization and hyperpolarization of the cell. $A$ : depolarization of TC cell prevented deinactivation of the low-threshold current during RE-evoked IPSP that resulted in the absence of the LT spikes. $B$ : for $\mathrm{DC}=0$ the $\mathrm{TC}$ cell displayed a fast augmentation of the responses that achieved a maximal strength after the 4th shock. $C$ : at negative levels of DC current the TC cell was hyperpolarized and low-threshold $\mathrm{Ca}^{2+}$ current was deinactivated completely before stimulation. Train of shocks evoked a decremental response because of the partial inactivation of the low-threshold $\mathrm{Ca}^{2+}$ current. 
A

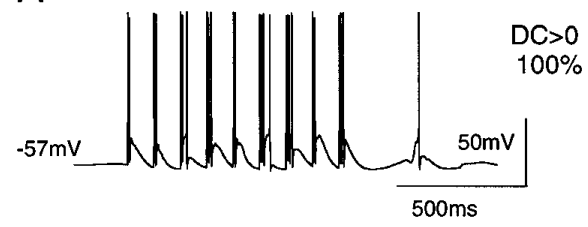

B
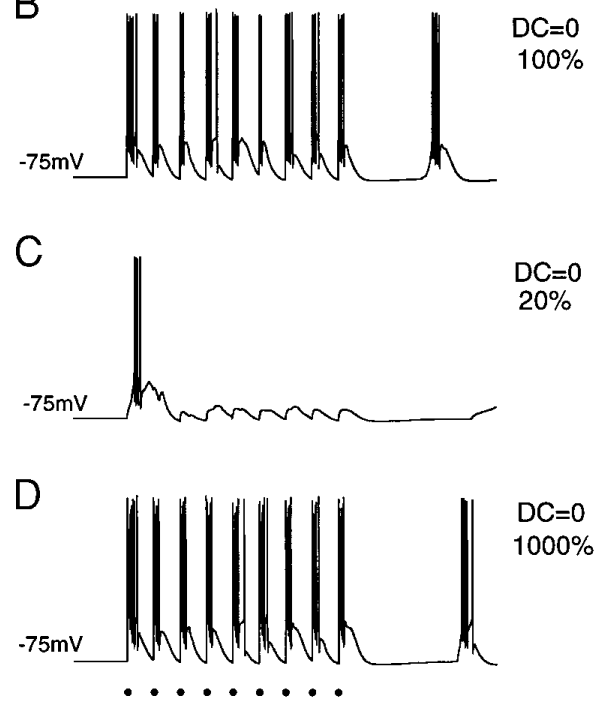
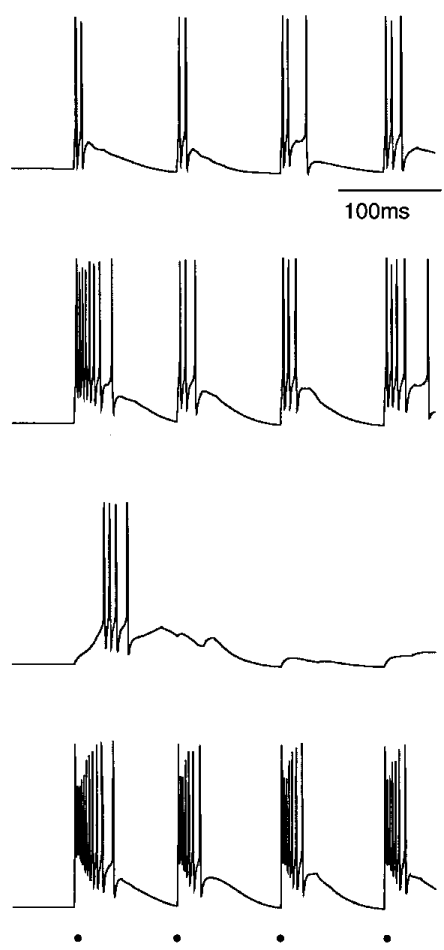

FIG. 12. Role of membrane potential and intensity of stimulation in augmenting responses of RE cells. One RE cell is shown at different levels of DC ( $A$ and $B$ ) and for different stimulus intensities ( $C$ and $D)\left(g_{\mathrm{GABA}_{A}(\mathrm{RE})}=0.07 \mu \mathrm{S}\right.$, $\left.g_{\mathrm{GABA}_{\mathrm{A}}(\mathrm{TC})}=0.02 \mu \mathrm{S}, g_{\mathrm{GABA}_{\mathrm{B}}}=0.2 \mu \mathrm{S}, g_{\mathrm{AMPA}}=0.07 \mu \mathrm{S}\right)$. Responses to the first 4 stimuli at $10 \mathrm{~Hz}$ are expanded at right. $A$ : depolarization of the RE cell by positive DC led to the complete inactivation of the low-threshold current at rest. It eliminated diminishing of the RE bursts for the 2nd shock, and the RE cell displayed augmenting responses during whole train of stimuli. $B$ : responses of the RE cell for $\mathrm{DC}=0$. First burst discharge in RE cell led to additional inactivation of $I_{\mathrm{T}}$ current that resulted in the diminishing of TC responses for the 2nd shock. $C$ : RE cell during low intensity stimulation $\left(g_{\text {ext }}=0.1 \mu \mathrm{S}\right)$. Forementioned inactivation of the low-threshold current during 1st burst discharge in RE cell resulted in the lack of action potentials starting from the 2 nd stimulus in the train. $D:$ RE cell during high-intensity stimulation $\left(g_{\text {ext }}=\right.$ $5 \mu \mathrm{S})$. Slight diminishing of the burst discharge was observed after the 2 nd shock. From the 2 nd stimulus, the RE cell displayed an unaugmented response. in TC cells during repetitive stimulation. RE-evoked IPSPs that hyperpolarized the TC cells were responsible for this deinactivation. Thus the strength of synaptic coupling between RE and TC cells affected the development of augmenting responses. To determine the influence of different synaptic conductances, we varied their strengths in the chain of coupled RE-TC cells.

Figure $14, A-C$, shows the influence of changing the strength of $\mathrm{GABA}_{\mathrm{B}}$ inhibition on augmentation of TC responses during repetitive stimulation. One arbitrarily selected $\mathrm{TC}$ cell is shown. Blocking the $\mathrm{GABA}_{\mathrm{B}}$ receptors (see Fig. 14A) eliminated the augmentation. Although RE-

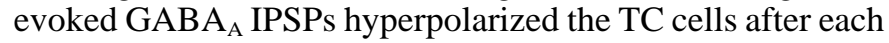
shock, the magnitude of the hyperpolarization was not enough to deinactivate the low-threshold $\mathrm{Ca}^{2+}$ current, and the TC cells displayed similar responses during whole train of stimuli. The absence of the action potential after the first stimulus was a result of the strong $\mathrm{GABA}_{\mathrm{A}}$ IPSP evoked by the powerful first spike burst in RE cells. When $\mathrm{GABA}_{B}$ inhibition was included, the TC cells displayed incremental responses during a train of stimuli (see Fig. 14, $B$ and $C$ ) by the low-threshold mechanism of augmentation.

Figure $14, D-F$, shows the effect of varying the $\mathrm{GABA}_{\mathrm{A}}$ inhibition between RE cells and from RE cells to TC cells. Increasing the lateral $\mathrm{GABA}_{\mathrm{A}}$ inhibition (Fig. 14D) diminished the burst discharges in RE cells, which resulted in the weakening of $\mathrm{GABA}_{\mathrm{B}}$ IPSPs and slowing of the augmenting responses in the TC cells (compare Fig. 14, $D$ with $C$ ). The $\mathrm{GABA}_{\mathrm{A}}$ component of RE-evoked IPSP was also weaker, giving rise to a single action potential in the TC cell after

A
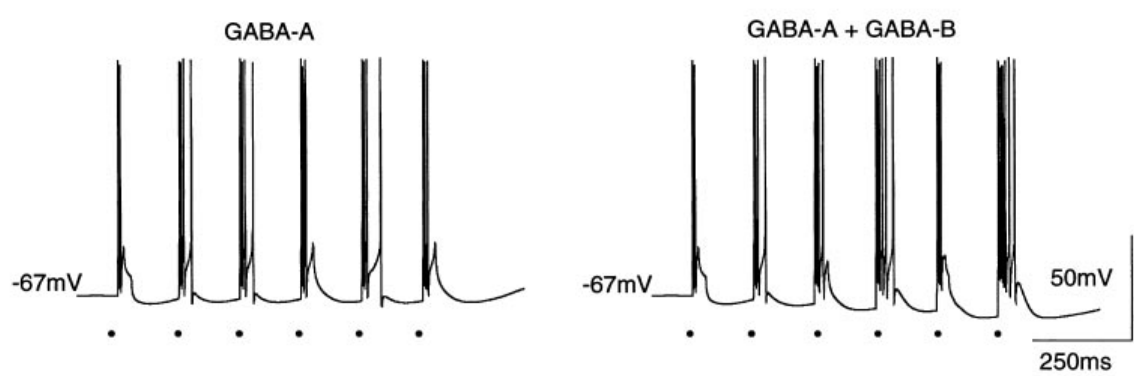

B

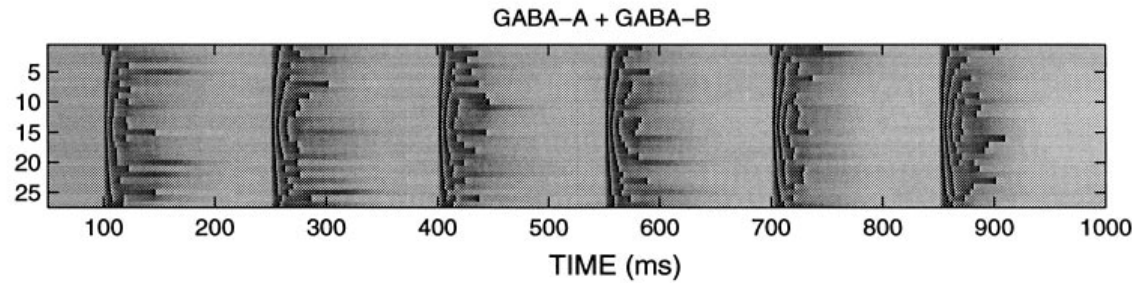

FIG. 13. Response of RE cells from an isolated reticular nucleus during $8 \mathrm{~Hz}$ stimulation $\left(g_{\mathrm{GABA}_{\mathrm{A}}(\mathrm{RE})}=0.07 \mu \mathrm{S}\right) . A$ : reciprocal pair of RE cells: only $\mathrm{GABA}_{\mathrm{A}}$ coupling between RE cells (left) and mixed $\mathrm{GABA}_{\mathrm{A}}-\mathrm{GABA}_{\mathrm{B}}$ coupling $\left(g_{\mathrm{GABA}_{\mathrm{B}}(\mathrm{RE})}=0.02 \mu \mathrm{S}\right.$; right $) . B: 1$-dimensional network of RE cells with mixed $\mathrm{GABA}_{\mathrm{A}}-\mathrm{GABA}_{\mathrm{B}}$ coupling. Weak lateral $\mathrm{GABA}_{\mathrm{B}}$ inhibition between RE cells led to the augmentation of the RE responses that was absent for $\mathrm{GABA}_{\mathrm{A}}$ coupling alone. Augmentation was based on deinactivation of the low-threshold $\mathrm{Ca}^{2+}$ current in the RE cells during $\mathrm{GABA}_{\mathrm{B}}$ phase of IPSP. Value of membrane potential for each neuron is coded in grey scale from $-90 \mathrm{mV}$ (white) to $-30 \mathrm{mV}$ (black). 


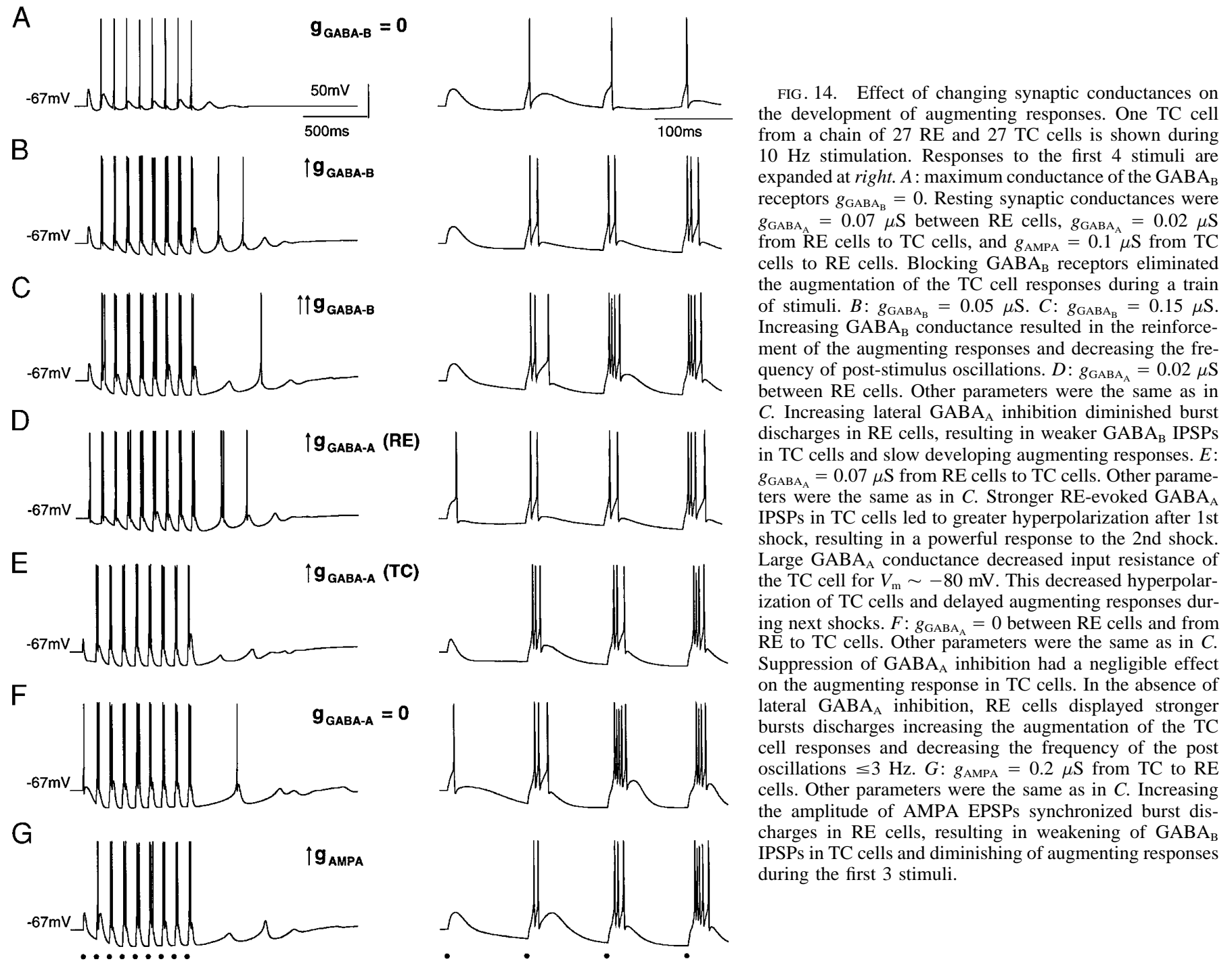

the first stimulus. The main effect of making the $\mathrm{GABA}_{\mathrm{A}}$ inhibition stronger from the RE to TC cells (see Fig. 14E) was a faster hyperpolarization of TC cells after the first stimulus. High $\mathrm{GABA}_{\mathrm{A}}$ conductance also decreased the input resistance of a TC cells near the level of reverse potential and consequently decreased the maximal hyperpolarization elicited by $\mathrm{GABA}_{\mathrm{B}}$ IPSPs during a train of stimuli. Figure $14 \mathrm{~F}$ shows the responses of a TC cell after blocking both RE-RE and RE-TC GABA $A_{A}$ receptors. In the absence the lateral $\mathrm{GABA}_{\mathrm{A}}$ inhibition between RE cells, powerful burst discharges occurred in the RE cells and bursts in the TC cells augmented rapidly.

Figure $14 G$ shows TC cell responses after increasing the AMPA conductance. Powerful AMPA EPSPs delivered to RE cells elicited synchronous burst discharges that were similar to responses that occurred when the RE cells had identical parameters. Under these conditions, the lateral $\mathrm{GABA}_{\mathrm{A}}$ inhibition more effectively decreased the duration of the RE bursts. The result was weaker $\mathrm{GABA}_{\mathrm{B}}$ IPSPs and delayed augmenting responses in the TC cells (compare Fig. 14, $G$ with $C$ ).

All of the evidence presented thus far suggests that a necessary condition for thalamic augmentation is the pres- ence of $\mathrm{GABA}_{\mathrm{B}}$ synapses between RE and TC cells. Increasing the $\mathrm{GABA}_{\mathrm{B}}$ conductance made the augmenting response develop faster. In comparison, increasing of $\mathrm{GABA}_{\mathrm{A}}$ and AMPA conductances diminished the augmentation of TC cell responses.

\section{Intrinsic conductances}

The intrinsic properties of RE and TC cells have a profound influence on the character of thalamic responses during repetitive stimulation. Here we examine the role of some of the intrinsic currents using simulations of the RE-TC chain.

Deinactivation of the low-threshold $\mathrm{Ca}^{2+}$ current in thalamic relay cells during repetitive stimulation is caused by the RE-evoked IPSPs. Decreasing the maximal conductance of $I_{\mathrm{T}}$ current in RE cells weakened burst discharges in RE cells (by decreasing the amplitude of the LTSs) and diminished the IPSPs in TC cells. As a consequence, the deinactivation of $I_{\mathrm{T}}$ current in TC cells was weakened and the augmenting responses were delayed (compare Fig. 15, $A$ with $B$ ).

Figure $15 C$ shows the dependence of the RE-TC responses on the low-threshold $\mathrm{Ca}^{2+}$ current in the TC cells. Decreas- 
A

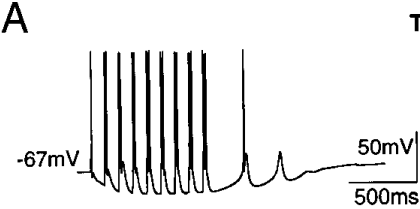

B

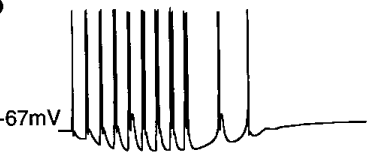

C

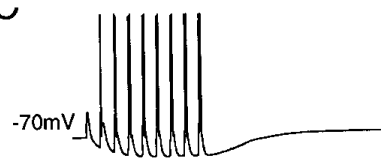

D

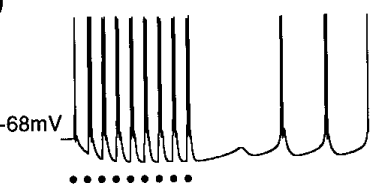

TC
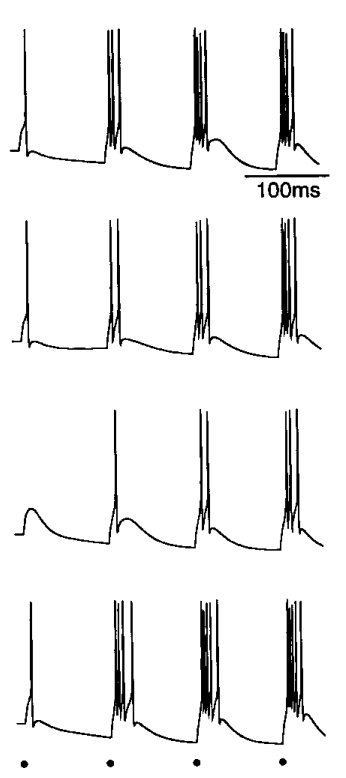

RE

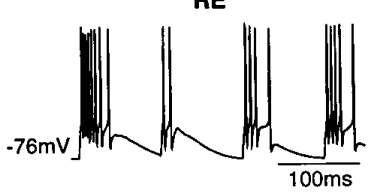

$\mathbf{g}_{\text {T(RE) }}$

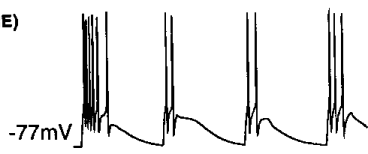

$\mid \mathbf{g}_{\mathrm{T}(\mathrm{TC})}$

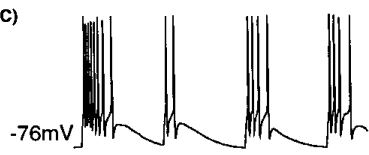

$\sqrt{1} \mathbf{g}_{\mathrm{n}}$

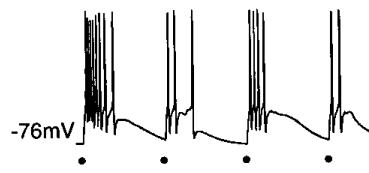

FIG. 15. Effect of intrinsic conductances on the development of augmenting responses. One TC and $1 \mathrm{RE}$ cell from a chain of 27 $\mathrm{RE}$ and $27 \mathrm{TC}$ cells is shown during $10 \mathrm{~Hz}$ stimulation. Responses of a TC cell to the first 4 stimuli are expanded at right (second column) on a different time scale. $A$ : responses for "basic" values of intrinsic conductances: $g_{\mathrm{T}_{\mathrm{RE}}}=2 \mu \mathrm{S} / \mathrm{cm}^{2}, g_{\mathrm{T}_{\mathrm{TC}}}=2.2 \mu \mathrm{S} /$ $\mathrm{cm}^{2}, g_{\mathrm{h}}=0.02 \mu \mathrm{S} / \mathrm{cm}^{2} . B: g_{\mathrm{T}_{\mathrm{PE}}}=1.2 \mu \mathrm{S} /$ $\mathrm{cm}^{2}$. Other parameters were the same as in $A$. Decreasing low-threshold $\mathrm{Ca}^{2+}$ conductance in RE cells diminished burst discharges in these cells and resulted in weaker $\mathrm{GABA}_{\mathrm{B}}$ IPSPs and slow developing augmenting responses. $C: g_{\mathrm{T}_{\mathrm{TC}}}=1.2 \mu \mathrm{S} / \mathrm{cm}^{2}$. Other parameters were the same as in $A$. Weaker lowthreshold $\mathrm{Ca}^{2+}$ conductance in TC cells diminished the excitability of these cells and decreased the augmentation of TC responses. $D: g_{\mathrm{h}}=0.007 \mu \mathrm{S} / \mathrm{cm}^{2}$. Other parameters were the same as in $A$. Decreasing $I_{\mathrm{h}}$ current resulted in faster RE-evoked hyperpolarization of TC cells and augmentation of their responses. Train of shocks was followed by $3-\mathrm{Hz}$ delta oscillations. ing the maximal conductance for the $I_{\mathrm{T}}$ current diminished the amplitude of LTSs in TC cells, and weaker augmenting responses were observed during repetitive stimulation (cf. Fig. 15, $A$ with $C$ ). Blocking the $I_{\mathrm{T}}$ channels blocked augmentation, and the TC cells responded with similar (nonaugmenting) responses throughout the entire train of stimuli (not shown).

Figure $15 D$ shows the effect of reducing the $I_{\mathrm{h}}$ current on thalamic augmentation. $I_{\mathrm{h}}$ is a depolarizing current activated by hyperpolarization of the TC cell. Decreasing the $I_{\mathrm{h}}$ con- ductance resulted in greater hyperpolarization of the TC cells and, consequently, more powerful LTSs in the TC cells in response to the stimulation.

Thus the low-threshold $\mathrm{Ca}^{2+}$ current is an essential intrinsic current for eliciting augmenting responses during repetitive stimulation. However, the thalamocortical network displayed a robust augmenting response for a wide range of parameters for the synaptic and intrinsic currents. As a consequence, the proposed mechanism for augmentation is not parameter specific.
$(2,2)$

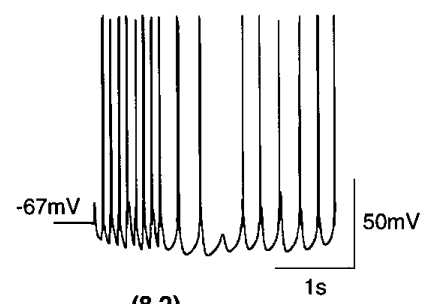

$(8,2)$

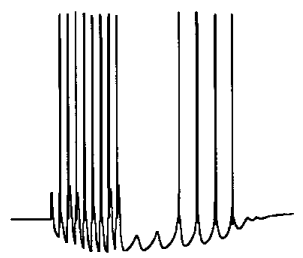

$(14,2)$

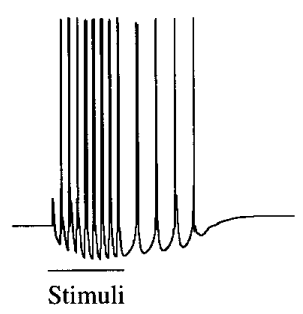

$(2,8)$
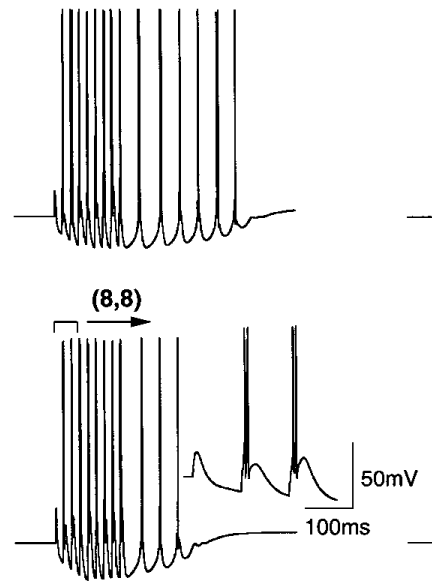

$(14,8)$

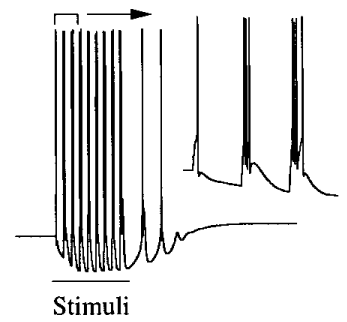

$(2,14)$

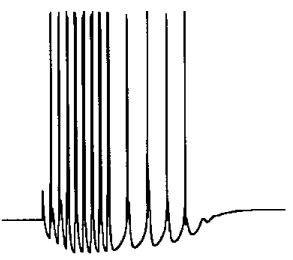

$(8,14)$

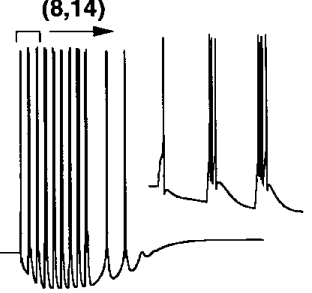

$(14,14)$

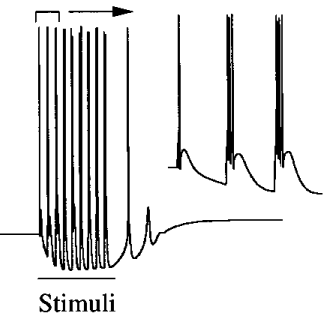

FIG. 16. Augmenting responses in a 2-dimensional array of $27 \times 27 \mathrm{RE}$ and $27 \times 27 \mathrm{TC}$ cells. Responses of 9 TC cells located in the different regions of the network are shown. Top left: corresponds to the cell from the top left corner of the network [coordinates $(2,2)]$. Bottom right: corresponds to the cell from the center of network [coordinates $(14,14)]$. Insets: responses to the first 3 stimuli, on a different time scale. Intensity of stimulation was maximal in the center of the network and decayed exponentially in all directions. Augmenting responses in a 2-dimensional network demonstrated the same features as in a 1-dimensional chain. Cells from the center displayed strong augmentation of responses and fast termination of the poststimulus oscillations. Boundary cells received a low-intensity stimulation and demonstrated delayed augmenting responses followed by prolonged slow oscillations. 


\section{Two-dimensional network}

A one-dimensional chain of RE and TC cells is a crude approximation to thalamic anatomy. Here we consider a twodimensional network of $N \times N$ RE and $N \times N$ TC cells. We use "dense proximal connections" (Destexhe et al. 1994a) in which each RE cell is connected to all other RE and TC cells within some radius $R_{\mathrm{RE}}$ and each TC cell is connected to all RE cells within radius $R_{\mathrm{TC}}$.

Figure 16 shows the responses of equidistant TC cells from a network with $N=27$ and $27 \times 27=729$ thalamic relay cells. TC cells located close to the center of the network (bottom right) had strong and rapid augmentation of responses (from 1 to 4 spikes) during a train of stimuli and only a few cycles of poststimulus oscillations. In contrast, the TC cells located close to the boundary of the network (top left) displayed a weak augmenting response (from 0 to 2 spikes) followed by prolonged slow oscillations.

The difference between central and boundary neurons was in the intensity of stimulation. The cells located near the center of the network received powerful RE-evoked GABA IPSPs and were strongly hyperpolarized after the first 1-2 stimuli. This resulted in the complete deinactivation of the low-threshold $\mathrm{Ca}^{2+}$ current and large LTSs. The neurons far from the center of the stimulation received weaker input that resulted in smaller GABA ${ }_{B}$ IPSPs in TC cells and only partial deinactivation of the low-threshold $\mathrm{Ca}^{2+}$ current during stimulation.

In the two-dimensional network, the contribution of the each individual cell to the whole PSP was much smaller than for the one-dimensional chain. Therefore the mechanism of desynchronization based on the variability of parameters was more effective in the two-dimensional network than in onedimensional chain. The result was a faster desynchronization and termination of the poststimulus oscillations in the twodimensional network.

In general, the network geometry does not have a critical role in the proposed mechanism for augmentation. Both oneand two-dimensional networks displayed similar augmenting responses during a train of stimuli.

\section{IS C U S S ION}

The results of simulations presented in this paper show that the known intrinsic and synaptic properties of TC and RE cells, along with the intrathalamic connectivity, are sufficient to generate augmenting responses to direct stimulation of the thalamus; a network consisting of one TC and one RE cell is the smallest circuit capable of generating augmenting responses with the same properties as those observed experimentally in vivo; increasing the number of cells in the network leads to faster buildup and stronger augmenting responses; a small $(\sim 10 \%)$ variability of the parameters in the model enhances the augmentation and prevents poststimulus oscillations due to faster desynchronization; the two essential mechanisms needed for the generation of augmenting responses are the low-threshold $\mathrm{Ca}^{2+}$ current and $\mathrm{GABA}_{\mathrm{B}}$ inhibition; and the augmentation that is observed in regions of the thalamus remote from the site of stimulation could be accounted for by recruitment of TC cells through the lateral connectivity between the inhibitory cells in the RE nucleus.
Although the computational analysis of thalamic augmenting responses presented in this paper was motivated by in vivo recordings from the thalamus of anesthetized cats, the model RE-TC network studied here is not species specific. Only the most basic properties of RE and TC cells and synaptic interconnections were included in the model. The robustness of the results were tested over a wide range of intrinsic and synaptic parameters, including the radii of synaptic interconnections. Thus augmenting responses during repetitive stimulation may arise from general properties of thalamic relay neurons and synaptic interconnections in the intact thalamus.

\section{Thalamic relay cells during repetitive stimulation}

In vivo recordings from the dorsal thalamus of decorticated cats anesthetized with ketamine and xylazine have revealed a low-threshold augmenting response generated in the thalamus (Steriade and Timofeev 1997; Timofeev and Steriade 1998). Augmentation was characterized by a progressive hyperpolarization of TC cells during repetitive stimulation. The model of the thalamic network examined in this paper shows that both synaptic interactions and intrinsic currents contribute to generating augmenting responses. A thalamic stimulus produces an EPSP followed by the REinduced IPSP in the TC cell, which deinactivates the lowthreshold $\mathrm{Ca}^{2+}$ current. The next EPSP then is followed by the LTS. Progressive recruitment of TC cells in the network occurs through $\mathrm{GABA}_{\mathrm{B}}$ IPSP responses.

Deinactivation of the low-threshold $\mathrm{Ca}^{2+}$ current determines a frequency window $(5-15 \mathrm{~Hz})$ where the low-threshold mechanism for augmentation is effective. For high-frequency stimulation $(>20 \mathrm{~Hz})$, the time intervals are not long enough to deinactivate the $I_{\mathrm{T}}$ current. If the frequency of stimulation is too low $(<3 \mathrm{~Hz})$, then TC cells display rebound-burst inactivating $I_{\mathrm{T}}$ current before the second stimulus occurs. In both cases, the second stimulus in the train is not followed by LTS and augmentation does not occur (see Fig. 5).

The strength of the $\mathrm{GABA}_{\mathrm{B}}$ IPSP is an important parameter for controlling the development of augmenting responses. Reducing the RE-evoked GABA ${ }_{B}$ IPSP in TC cell reduced the partial deinactivation of the low-threshold $\mathrm{Ca}^{2+}$ current and delayed the augmenting responses in TC cell. Blocking the $\mathrm{GABA}_{\mathrm{B}}$ receptors blocked augmentation and resulted in stereotyped responses in the TC cells during repetitive stimulation.

One of the mechanisms reducing $\mathrm{GABA}_{\mathrm{B}}$ IPSPs in TC cells is a lateral $\mathrm{GABA}_{\mathrm{A}}$ inhibition between RE neurons. It has been reported (Huguenard and Prince 1994) that application of the $\mathrm{GABA}_{A}$ agonist clonazepam decreased the $\mathrm{GABA}_{\mathrm{B}}$ component of the RE-evoked IPSP in TC cells. We have found that this mechanism is especially effective if RE cells are made identical. Even a small variability in the parameters of the neurons leads to the nonsynchronous firing of RE cells and greatly increases GABA $A_{B}$ IPSPs in TC cells.

The low-threshold mechanism for augmentation based on the deinactivation of $I_{\mathrm{T}}$ current explored here is highly robust to varying the parameters of synaptic and intrinsic currents. Except for a complete block of $\mathrm{GABA}_{B}$ receptors, changing the synaptic conductances in the model had only a small qualitative effect on the augmenting responses in the TC 
cells. Augmentation also is observed over a wide range of the values of the intrinsic conductances. However, blocking the $I_{\mathrm{T}}$ currents in the TC and RE cells leads to nonaugmenting responses during repetitive stimulation. Depolarizing TC cells had the same effect as blocking the $I_{\mathrm{T}}$ currents because depolarization inactivates the $I_{\mathrm{T}}$ current and prevents it from becoming deinactivation during RE-evoked IPSPs.

The model of the TC cell used here included $\mathrm{Ca}^{2+}$ regulation of $I_{\mathrm{h}}$ current (Destexhe et al. 1996a). However, the role of intracellular $\mathrm{Ca}^{2+}$ concentration in the regulation of $I_{\mathrm{h}}$ conductance is uncertain. In one study that used $\mathrm{Ca}^{2+}$-sensitive fluorescent dyes, regulation by intracellular $\mathrm{Ca}^{2+}$ was not observed (Budde et al. 1997), whereas in another study based on the release of caged-Ca ${ }^{2+}$, regulation of the $I_{\mathrm{h}}$ conductance in TC cells was observed (Lüthi and McCormick 1997). The proposed low-threshold mechanism for augmentation demonstrated here does not depend on the $\mathrm{Ca}^{2+}$ regulation of $I_{\mathrm{h}}$ current. Even after greatly decreasing the $I_{\mathrm{h}}$ conductance, TC cells displayed strong augmenting responses during repetitive stimulation.

In contrast to thalamic stimulation, repetitive prethalamic stimulation of ascending afferent pathways evokes nonaugmented responses in TC cells. This is similar to the absence of spindles when prethalamic stimuli are used compared with powerful spindle oscillations evoked by corticothalamic stimulation (Steriade 1984; Steriade et al. 1972). This difference can be explained by the fact that the former stimulation does not directly activate RE neurons, whereas the latter form of stimulation does. Based on the computer model, we propose that one of the reasons for this difference is that in the experiments with prethalamic (brachium conjunctivum) shocks there might have been exclusive monosynaptic stimulation of TC cells. We found that weak stimulation of TC cells without stimulating the RE cells resulted in nonaugmented TC responses throughout the train of stimuli. In contrast, the additional stimulation of RE neurons led to augmenting responses in TC cells. For high-intensity stimulation, simultaneous stimulation of dorsal thalamic and RE nuclei increased the duration of the burst discharges in RE cells, which led to the strengthening of $\mathrm{GABA}_{B}$ IPSPs and more rapid augmentation of responses in the TC cells. This prediction of the model could be tested by recording from RE cells during repetitive prethalamic stimulation of ascending afferent pathways.

The properties of augmenting responses in TC cells in the model depended on their position relative to the site of stimulation. TC cells located near the center of stimulation displayed rapid augmentation followed by one to two cycles of slow oscillations. TC cells located far from the site of stimulation had weak augmentation and prolonged poststimulus oscillations. The frequency of these self-sustained oscillations was 3-4 Hz, which is in the range of the delta rhythm (McCormick and Pape 1990; Leresche et al. 1991; Soltesz et al. 1991; Steriade et al. 1991). Delta oscillations can be generated in a single TC cell that is hyperpolarized as a result of the interplay between low-threshold $\left(I_{\mathrm{T}}\right)$ and hyperpolarization-activated cation $\left(I_{\mathrm{h}}\right)$ currents. However, in the present model, the generation of the slow poststimulus oscillations depended on inhibitory RE neurons. Synchronous burst discharges in RE cells induced a fast hyperpolarization of TC cells that activated the $I_{\mathrm{h}}$ current. This led to the depolarization of TC cells, followed by LTSs and rebound bursts. Finally, burst discharges in TC cells evoked EPSPs and new bursts in RE cells. Progressive desynchronization of the network in the absence of external stimulation decreased the amplitude of the summed IPSPs in the TC cells and led to the termination of poststimulus oscillations.

In in vivo experiments, thalamic stimulation evoked synchronous activation in a large population of RE cells and resulted in strong $\mathrm{GABA}_{\mathrm{B}}$ IPSPs in related TC cells. In the absence of strong stimulation, the spatio-temporal coherence in the thalamocortical network was much too low to produce strong activation of the $\mathrm{GABA}_{B}$ receptors and as a consequence the $\mathrm{GABA}_{B}$ IPSPs were reduced in TC cells.

In a cortical slice preparation, the activation of $\mathrm{GABA}_{\mathrm{B}}$ IPSPs can be achieved only when presynaptic spikes from inhibitory interneurons fire in bursts (Thomson et al. 1996). However, even a burst of spikes from a single RE cell cannot induce a $\mathrm{GABA}_{\mathrm{B}}$ IPSP in postsynaptic TC cell (Cox et al. 1997; Sanchez-Vives and McCormick 1997; Sanchez-Vives et al. 1997); rather, bursts from multiple RE cells are needed to induce a $\mathrm{GABA}_{\mathrm{B}}$ IPSP in a TC cell. During naturally occurring spindles the interaction between dorsal thalamic and RE nuclei is determined mainly by $\mathrm{GABA}_{\mathrm{A}}$ and AMPA currents. In the present model, the size of the thalamic pool was relatively small, and the effects of strong $\mathrm{GABA}_{\mathrm{B}}$ inhibition were taken into account by increasing the maximal conductance for $\mathrm{GABA}_{\mathrm{B}}$ synapses. This gave rapid augmentation of the responses in TC cells during a train of stimuli; however, the spindle oscillations evoked by a single thalamic shock was transformed after a few cycles into slow (3-4 $\mathrm{Hz}$ ) oscillations.

A one-dimensional chain of TC and RE cells is only a crude approximation of thalamic anatomy. To test the possible effects of a more complex geometry, we considered a two-dimensional network of RE-TC cells. The main features of augmenting responses found in one-dimensional chaina decrease of augmentation and an increase in the duration of poststimulus oscillations with distance from the site of stimulation-were found also in the two-dimensional model. However, diminishing the contribution of individual presynaptic cells to the postsynaptic PSP in a two-dimensional network led to faster desynchronization of the network and rapid termination of post-stimulus oscillations.

\section{$R E$ cells during repetitive stimulation}

$\mathrm{RE}$ cells are critical in generating augmenting responses in TC cells. Powerful IPSPs delivered from RE cells deinactivated the low-threshold $\mathrm{Ca}^{2+}$ current and set up conditions for augmentation to occur in the responses of the thalamic relay cells. The pattern of responses in RE cells during repetitive stimulation was more complex than in TC cells. The resting membrane potential of RE cells in the model was around $-75 \mathrm{mV}$, based on in vitro recordings, slightly more negative than in vivo. The low-threshold $\mathrm{Ca}^{2+}$ current in $\mathrm{RE}$ cells was deinactivated partially at this level, and the first stimulus in the train elicited a powerful burst discharge (usually $\sim 5-10$ spikes ). Depolarization of the RE cells inactivated $I_{\mathrm{T}}$ channels and the next stimulus evoked weaker responses. However, the buildup of TC-evoked EPSPs led to the slow augmentation of RE responses starting from the third stimulus. These features were especially prominent during low-intensity stimulation. In this case, the burst discharge 
evoked by the first EPSP in the train was followed by EPSPs without action potential during rest of train. This result is in a good agreement with the in vivo data (Timofeev and Steriade 1998). However, we could not duplicate the experimentally observed augmentation of RE cell responses during the entire train of stimuli for high-intensity stimulation. One possible explanation is that the RE cells in the model were more hyperpolarized than those recorded in vivo. To test this possibility, we injected positive DC current and found that depolarization of RE cells led to weaker but monotonically increasing responses, which were more similar to in vivo responses. Another result of depolarization was weaker IPSPs in TC cells and delayed augmentation. These results may depend on our use of a one-compartment model for the $\mathrm{RE}$ cell. There is experimental evidence and corroborating models showing that the low-threshold $\mathrm{Ca}^{2+}$ currents are located in the distal dendrites of RE cells (Destexhe et al. 1996b). Hyperpolarization of the distal dendrites would lead to the deinactivation of the $I_{\mathrm{T}}$ current despite more elevated membrane potentials in the somas of RE cells.

One explanation for the augmenting responses in RE cells during repetitive stimulation was based on the buildup of TC-evoked EPSPs. An additional contribution to the augmenting response of the RE cells could be through a lowthreshold mechanism similar to that described for TC cells. It has been reported that synaptic connections between RE cells contain a weak $\mathrm{GABA}_{\mathrm{B}}$ component (Sanchez-Vives et al. 1997; Ulrich and Huguenard 1996). Including intrareticular $\mathrm{GABA}_{\mathrm{B}}$ conductances in the model would result in weak augmentation of the responses of RE cells in the isolated reticular nucleus during repetitive stimulation. The lowthreshold mechanism for augmentation of RE responses is especially effective during high-intensity stimulation. In this case, the powerful burst discharges in the RE cells lead to exalted activation of $\mathrm{GABA}_{\mathrm{B}}$ receptors and deinactivation of $I_{\mathrm{T}}$ channels.

\section{Predictions of the model}

Our analysis of thalamocortical augmenting responses in RE-TC networks makes several predictions that can be tested experimentally.

Activation of the $\mathrm{GABA}_{\mathrm{B}}$ synaptic interconnections from $\mathrm{RE}$ to TC cells is necessary for augmenting responses to occur in TC cells during repetitive stimulation. Blockade of $\mathrm{GABA}_{\mathrm{B}}$ receptors in the model of the RE-TC network transformed the augmenting responses of TC cells into almost stereotyped responses.

Stimulation of only the TC cells at low and moderate intensities failed to produce strong activation of RE cells and

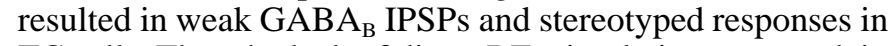
TC cells. Thus the lack of direct RE stimulation may explain the stereotyped responses of TC cells in the experiments where the brachium conjunctivum pathway was stimulated.

Simultaneous activation of RE and TC cells is necessary for augmenting responses in TC cells during repetitive stimulation. During appropriate phases of spontaneous sleep oscillations, the intrathalamic stimulation activating both RE and TC neurons may result in immediate augmentation and selfsustained activity (M. Steriade, I. Timofeev, and F. Grenier, unpublished data). Thus the inputs that activate both RE and TC cells, such as corticothalamic volleys, may induce a transition from sleep rhythms to spike-wave seizures.
The model of an isolated RE nucleus displayed augmenting responses during repetitive stimulation. In slice experiments, direct electrical stimulation of RE cells may result in the activation of relatively weak $\mathrm{GABA}_{\mathrm{B}}$ interconnections between RE cells (Sanchez-Vives et al. 1997; Ulrich and Huguenard 1996), which leads to their hyperpolarization and LTSs. One of the consequences intrareticular augmentation is to reinforce $\mathrm{GABA}_{\mathrm{B}}$ IPSPs in TC cells.

Poststimulus oscillations after an augmenting response in the model were terminated after several cycles. This suggests that the thalamus itself after overexcitation may not be able to maintain long-lasting epileptic-like oscillations without cortical feedback. The appearance of paroxysmal activity in intact thalamocortical systems may depend on cortical mechanisms.

Our model predicts that intrathalamic mechanisms might make a major contribution to cortical augmenting responses during repetitive thalamic stimulation. In turn, cortical feedback could promote augmentation in the thalamus through mechanisms similar to those that are involved in the generation of spindles (Contreras and Steriade 1996; Contreras et al. 1997). The contribution of cortical EPSPs to intrathalamic augmenting responses may be increased by intracortical short term plasticity such as paired-pulse facilitation (Castro-Alamancos and Connors 1996b; Metherate and Ashe 1994).

Finally, augmenting responses in the cortex induced by intrathalamic mechanisms should arise first in cortical layers innervated by thalamocortical inputs. This agrees with previous data (Castro-Alamancos and Connors 1996a; Kandel and Buzsáki 1997) and with our recent experimental and modeling results, which will be presented in forthcoming papers.

\section{APPENDIX}

The membrane potentials of RE and TC neurons are governed by the equations

$$
\begin{gathered}
C_{\mathrm{m}} \frac{\mathrm{d} V_{\mathrm{RE}}}{\mathrm{d} t}=-g_{\mathrm{L}}\left(V_{\mathrm{RE}}-E_{\mathrm{L}}\right)-I_{\mathrm{Na}}-I_{\mathrm{K}}-I_{\mathrm{T}_{\mathrm{RE}}}-I_{\mathrm{GABA}_{\mathrm{A}}}-I_{\mathrm{AMPA}}-I_{\mathrm{AMPA}_{\text {ext }}} \\
C_{\mathrm{m}} \frac{\mathrm{d} V_{\mathrm{TC}}}{\mathrm{d} t}=-g_{\mathrm{L}}\left(V_{\mathrm{TC}}-E_{\mathrm{L}}\right)-I_{\mathrm{Na}}-I_{\mathrm{K}}-I_{\mathrm{T}_{\mathrm{TC}}}-I_{\mathrm{h}}-I_{\mathrm{A}} \\
\quad-I_{\mathrm{GABA}_{\mathrm{A}}}-I_{\mathrm{GABA}_{\mathrm{B}}}-I_{\mathrm{AMPA}_{\text {ext }}}
\end{gathered}
$$

The passive parameters are $C_{\mathrm{m}}=1 \mu F / \mathrm{cm}^{2}, g_{\mathrm{L}}=0.01 \mathrm{mS} / \mathrm{cm}^{2}$, $E_{\mathrm{L}}=-70 \mathrm{mV}$ for TC cell (McCormick and Huguenard 1992) and $C_{\mathrm{m}}=1 \mu F / \mathrm{cm}^{2}, g_{\mathrm{L}}=0.05 \mathrm{mS} / \mathrm{cm}^{2}, E_{\mathrm{L}}=-77 \mathrm{mV}$ for RE cell (Destexhe et al. 1994a). The area of RE cell was $S_{\mathrm{RE}}=1.43 \cdot 10^{-4}$ $\mathrm{cm}^{2}$, and the area of TC cell was $S_{\mathrm{TC}}=2.9 \cdot 10^{-4} \mathrm{~cm}^{2}$.

\section{Intrinsic currents}

The voltage-dependent ionic currents $I_{\mathrm{Na}}, I_{\mathrm{K}}, I_{\mathrm{T}}$, and $I_{\mathrm{A}}$ are described by equation

$$
I_{j}^{\mathrm{int}}=g_{j} m^{\mathrm{M}} h^{\mathrm{N}}\left(V-E_{j}\right)
$$

where the maximal conductances and reverse potentials are $g_{\mathrm{T}}=$ $2.0 \mathrm{mS} / \mathrm{cm}^{2}, g_{\mathrm{Na}}=100 \mathrm{mS} / \mathrm{cm}^{2}, g_{\mathrm{K}}=10 \mathrm{mS} / \mathrm{cm}^{2}$ for RE cell and $g_{\mathrm{T}}=2.2 \mathrm{mS} / \mathrm{cm}^{2}, g_{\mathrm{Na}}=90 \mathrm{mS} / \mathrm{cm}^{2}, g_{\mathrm{K}}=10 \mathrm{mS} / \mathrm{cm}^{2}, g_{\mathrm{h}}=$ $0.02 \mathrm{mS} / \mathrm{cm}^{2}, g_{\mathrm{A}}=1.0 \mathrm{mS} / \mathrm{cm}^{2}$ for TC cell. For all cells, $E_{\mathrm{Na}}=$ $50 \mathrm{mV}, E_{\mathrm{K}}=-95 \mathrm{mV}$. The reversal potential for low-threshold $\mathrm{Ca}^{2+}$ current was calculated according to the Nerst equation $E_{\mathrm{T}}=$ 
$(R T / 2 F) \log \left([\mathrm{Ca}] /[\mathrm{Ca}]_{0}\right)$, where $R=8.31441 \mathrm{~J} /\left(\mathrm{mol}^{\circ} \mathrm{K}\right), T=$ $309.15^{\circ} \mathrm{K}, F=96,489 \mathrm{C} / \mathrm{mol}$, and $[\mathrm{Ca}]_{0}=2 \mathrm{mM}$.

The gating variables $0 \leq m(t), h(t) \leq 1$ satisfy

$$
\dot{m}=\left[m_{\infty}(V)-m\right] / \tau_{\mathrm{m}}(V), \quad \dot{h}=\left[h_{\infty}(V)-h\right] / \tau_{\mathrm{h}}(V)
$$

where $m_{\infty}(V), h_{\infty}(V), \tau_{\mathrm{m}}(V)$, and $\tau_{\mathrm{h}}(V)$ are nonlinear functions of $V$ extracted from experimental recordings of ionic currents. Gating kinetics was adjusted to $36^{\circ} \mathrm{C}$.

The $I_{\mathrm{T}_{\mathrm{RE}}}$ current for RE cells has (Destexhe et al. 1996b; Huguenard and Prince 1992) $M=2, N=1, m_{\infty}=1 /\{1+$ $\exp [-(V+52) / 7.4]\}, \tau_{\mathrm{m}}=(1+0.33 /\{\exp [(V+27) / 10]+$ $\exp [-(V+102) / 15]\}), h_{\infty}=1 /\{1+\exp [(V+80) / 5]\}, \tau_{\mathrm{h}}=$ $(22.7+0.27 /\{\exp [(V+48) / 4]+\exp [-(V+407) / 50]\})$.

The $I_{\mathrm{T}_{\mathrm{TC}}}$ current for TC cells has (Destexhe et al. 1996a; Huguenard and McCormick 1992) $M=2, N=1, m_{\infty}=1 /\{1+$ $\exp [-(V+59) / 6.2]\}, \tau_{\mathrm{m}}=(0.22 /\{\exp [-(V+132) / 16.7]+$ $\exp [(V+16.8) / 18.2]\}+0.13), h_{\infty}=1 /\{1+\exp [(V+83) 4]\}$, $\tau_{\mathrm{h}}=(8.2+\{56.6+0.27 \exp [(V+115.2) / 5]\} /\{1+\exp [(V+$ $86) / 3.2]\})$.

The $I_{\mathrm{A}}$ current for TC cells has (Huguenard and McCormick 1992) $M=4, N=1, m_{\infty}=1 /\{1+\exp [-(V+60) / 8.5]\}$; $\tau_{\mathrm{m}}=(0.27 /\{\exp [(V+35.8) / 19.7]+\exp [-(V+79.7) /$ $12.7]\}+0.1) ; h_{\infty}=1.0 /\{1+\exp [(V+78) / 6]\} ; \tau_{\mathrm{h}}=0.27 /$ $\{\exp [(V+46) / 5]+\exp [-(V+238) / 37.5]\}$ if $V<-63 \mathrm{mV}$ and $\tau_{\mathrm{h}}=5.1$ if $V>-63 \mathrm{mV}$.

The hyperpolarization-activated cation current $I_{\mathrm{h}}$ is described by (Destexhe et al. 1996a)

$$
I_{\mathrm{h}}=g_{\max }\left([O]+\mathrm{k}\left[O_{\mathrm{L}}\right]\right)\left(V-E_{\mathrm{h}}\right)
$$

where $k=2$ and $E_{\mathrm{h}}=-40 \mathrm{mV}$. The fraction of the channels in the opened $[O]$ and locked $\left[O_{\mathrm{L}}\right]$ forms were calculated according to the Eqs. 3 and 4 where $k_{1}=2.5 \times 10^{7} \mathrm{mM}^{-4} \mathrm{~ms}^{-1}, k_{2}=4 \times$ $10^{-4} \mathrm{~ms}^{-1}, k_{3}=0.1 \mathrm{~ms}^{-1}$, and $k_{4}=0.001 \mathrm{~ms}^{-1}$ are the constant rates and $\alpha(V)$ and $\beta(V)$ are the voltage-dependent transition rates (Huguenard and McCormick 1992; McCormick and Pape 1990): $\alpha=m_{\infty} / \tau_{\mathrm{m}}, \beta=\left(1-m_{\infty}\right) / \tau_{\mathrm{m}}, m_{\infty}=1 /\{1+\exp [(V+75) /$ $5.5]\} ; \tau_{\mathrm{m}}=(5.3+267 /\{\exp [(V+71.5) / 14.2]+\exp [-(V+$ 89)/11.6] \}).

The leak potassium current is $I_{\mathrm{KL}}=g_{\mathrm{KL}}\left(V-E_{\mathrm{KL}}\right.$ ) (McCormick and Huguenard 1992), where $g_{\mathrm{KL}}=0.005 \mathrm{mS} / \mathrm{cm}^{2}$ for RE cell and $g_{\mathrm{KL}}=0.012 \mathrm{mS} / \mathrm{cm}^{2}$ for TC cell.

For both the RE and TC cells, the $\mathrm{Ca}^{2+}$ dynamics is described by a simple first-order model (Destexhe et al. 1994a)

$$
\frac{\mathrm{d}[\mathrm{Ca}]}{\mathrm{d} t}=-A I_{\mathrm{T}}-\left([\mathrm{Ca}]-[\mathrm{Ca}]_{\infty}\right) / \tau
$$

where $[\mathrm{Ca}]_{\infty}=2.4 \cdot 10^{-4} \mathrm{mM}$ is equilibrium $\mathrm{Ca}^{2+}$ concentration, $A=5.18 \cdot 10^{-5} \mathrm{mM} \cdot \mathrm{cm}^{2} /(\mathrm{ms} \cdot \mu \mathrm{A})$ and $\tau=5 \mathrm{~ms}$.

\section{Synaptic currents}

$\mathrm{GABA}_{\mathrm{A}}$ and AMPA synaptic currents are given by

$$
I_{\text {syn }}=g_{\text {syn }}[O]\left(V-E_{\text {syn }}\right)
$$

where the reversal potential is $E_{\mathrm{AMPA}}=0 \mathrm{mV}$ for AMPA receptors and $E_{\mathrm{GABA}_{\mathrm{A}}}=-70 \mathrm{mV}$ for $\mathrm{GABA}_{\mathrm{A}}$ receptors in $\mathrm{RE}$ cells and $E_{\mathrm{GABA}_{\mathrm{A}}}=-80 \mathrm{mV}$ for $\mathrm{GABA}_{\mathrm{A}}$ receptors in TC cells (Ulrich and Huguenard 1997). The fraction of open channels $[O]$ is calculated according to $E q .7$

$$
\begin{aligned}
\frac{\mathrm{d}[O]}{\mathrm{d} t}=\alpha(1-[O])[T]-\beta[O], & \\
& {[T]=A \theta\left(t_{0}+t_{\max }-t\right) \theta\left(t-t_{0}\right) }
\end{aligned}
$$

where $\theta(x)$ is the Heaviside function and $t_{0}$ is the time instant of receptor activation. The parameters for the neurotransmitter pulse were amplitude $A=0.5$ and duration $t_{\max }=0.3 \mathrm{~ms}$. The rate constants, $\alpha$ and $\beta$, were $\alpha=20 \mathrm{~ms}$ and $\beta=0.16 \mathrm{~ms}$ for $\mathrm{GABA}_{\mathrm{A}}$ synapses and $\alpha=0.94 \mathrm{~ms}$ and $\beta=0.18 \mathrm{~ms}$ for AMPA synapses.

$\mathrm{GABA}_{\mathrm{B}}$ synaptic current is given by equation (Destexhe et al. 1996a)

$$
\begin{gathered}
I_{\mathrm{GABA}_{\mathrm{B}}}=g_{\mathrm{GABA}_{\mathrm{B}}} \frac{[G]^{4}}{[G]^{4}+K}\left(V-E_{\mathrm{K}}\right) \\
\frac{\mathrm{d}[R]}{\mathrm{d} t}=r_{1}(1-[R])[T]-r_{2}[R] \\
\frac{\mathrm{d}[G]}{\mathrm{d} t}=r_{3}[R]-r_{4}[G]
\end{gathered}
$$

where $[R](t)$ is the fraction of activated receptors, $[G](t)$ is the concentration of $\mathrm{G}$ proteins, and $E_{\mathrm{K}}=-95 \mathrm{mV}$ is potassium reverse potential. The rate constants were $r_{1}=0.5 \mathrm{mM}^{-1} \mathrm{~ms}^{-1}, r_{2}=$ $0.0012 \mathrm{~ms}^{-1}, r_{3}=0.1 \mathrm{~ms}^{-1}, r_{4}=0.034 \mathrm{~ms}^{-1}$, and $K=100 \mu \mathrm{M}^{4}$.

This research was supported by the Human Frontier Science Program, The Sloan Center for Theoretical Neurobiology, the Howard Hughes Medical Institute, the Medical Research Council of Canada, and the Savoy Foundation.

Address for reprint requests: T. J. Sejnowski, Howard Hughes Medical Institute, The Salk Institute, Computational Neurobiology Laboratory, 10010 North Torrey Pines Rd., La Jolla, CA 92037.

Received 8 October 1997; accepted in final form 23 December 1997.

\section{REFERENCES}

Budde, T., Biella, G., Munsch, T., AND PaPe, H. C. Lack of regulation by intracellular $\mathrm{Ca}^{2+}$ of the hyperpolarization-activated cation current in rat thalamic neurones. J. Physiol. (Lond.) 503: 79-85, 1997.

Castro-Alamancos, M. A. AND Connors, B. W. Spatiotemporal properties of short-term plasticity in sensorimotor thalamocortical pathways of the rat. J. Neurosci. 16: 2767-2779, 1996a.

Castro-Alamancos, M. A. and Connors, B. W. Cellular mechanisms of the augmenting response: short-term plasticity in a thalamocortical pathway. J. Neurosci. 16: 7742-7756, 1996b.

Castro-Alamancos, M. A. And Connors, B. W. Short-term plasticity of a thalamocortical pathway dynamically modulated by behavioral state. Science 272: 274-277, 1996c.

Castro-Alamancos, M. A. And Connors, B. W. Distinct forms of shortterm plasticity at excitatory synapses of hippocampus and neocortex. Proc. Natl. Acad. Sci. USA 94: 4161-4166, 1997.

Contreras, D., Destexhe, A., Sejnowski, T. J., and Steriade, M. Spatiotemporal patterns of spindle oscillations in cortex and thalamus. J. Neurosci. 17: 1179-1196, 1997.

Contreras, D. And STERIADE, M. Spindle oscillations in a cats: the role of cortico-thalamic feedback in thalamically generated rhythms. J. Physiol. (Lond.) 490: 159-180, 1996.

Cox, C. L., Huguenard, J. R., And Prince, D. A. Heterogeneous axonal arborizations of rat thalamic reticular neurons in the ventrobasal nucleus. J. Comp. Neurol. 366: 416-430, 1996.

Cox, C. L., Huguenard, J. R., And Prince, D. A. Nucleus reticularis neurons mediate diverse inhibitory effects in thalamus. Proc. Natl. Acad. Sci. USA 94: 8854-8859, 1997.

Crunelli, V., Haby, M., Jassik-Gerschenfeld, D., Leresche, N., AND PIRCHIO, $\mathrm{M} . ~ \mathrm{Cl}^{-}$and $\mathrm{K}^{+}$-dependent inhibitory postsynaptic potentials evoked by interneurones of the rat lateral geniculate nucleus. J. Physiol. (Lond.) 399: 153-176, 1988.

Dempsey, E. W. AND Morison, R. S. The electrical activity of a thalamocortical relay system. Am. J. Physiol. 138: 283-296, 1943.

Destexhe, A., Bal, T., McCormick, D. A., and Sejnowski, T. J. Ionic mechanisms underlying synchronized oscillations and propagating waves in a model of ferret thalamic slices. J. Neurophysiol. 76: 2049-2070, 1996 .

Destexhe, A., Contreras, D., Steriade, M., Sejnowski, T., and HugueNARD, J. R. In vivo, in vitro, and computational analysis of dendritic calcium currents in thalamic reticular neurons. J. Neurosci. 16: 169$185,1996 \mathrm{~b}$.

Destexhe, A., Contreras, D., Sejnowski, T. J., and Steriade, M. A model of spindle rhythmicity in the isolated thalamic reticular nucleus. J. Neurophysiol. 72: 803-818, 1994a. 
Destexhe, A., Mainen, Z. F., AND SejnOwski, T. J. Synthesis of models for excitable membranes, synaptic transmission and neuromodulation using a common kinetic formalism. J. Comp. Neurosci. 1: 195-230, 1994b.

DutAR, P. AND Nicoll, R. A. A physiological role for for $\mathrm{GABA}_{\mathrm{B}}$ receptors in the central nervous system. Nature 332: 156-158, 1988.

Enright, W. H., Higham, D. J., Owren, B., and Sharp, P. W. A survey of the explicit Runge-Kutta method. Available from ftp://ftp.cs.toronto.edu/ pub/reports/na/cs-94-291.ps.Z, 1995.

HIRSCH, J. C. AND BURNOD, Y. A synaptically evoked late hyperpolarization in the rat dorsolateral geniculate nucleus in vitro. Neuroscience 23: 457468, 1987.

Hodgkin, A. L. AND HuXley, A. F. A quantitative description of membrane current and its application to conduction and excitation in nerve. J. Physiol. (Lond.) 117: 500-544, 1952.

Houweling, A., Bazhenov, M., Sejnowski, T. J., Timofeev, I.. And SteriADE, M. Computational models of augmenting responses in thalamocortical networks. Soc. Neurosci. Abstr. 23: 514.10, 1997.

Huguenard, J. R., Coulter, D. A.. And McCormick, D. A. A fast transient potassium current in thalamic relay neurons: kinetics of activation and inactivation. J. Neurophysiol. 66: 1305-1315, 1991.

Huguenard, J. R. And McCormick, D. A. Simulation of the currents involved in rhythmic oscillations in thalamic relay neurons. J. Neurophysiol. 68: 1373-1383, 1992.

Huguenard, J. R. And Prince, D. A. A novel T-type current underlies prolonged $\mathrm{Ca}^{2+}$-dependent burst firing in GABAergic neurons of rat thalamic reticular nucleus. J. Neurosci. 12: 3804-3817, 1992.

Huguenard, J. R. And Prince, D. A. Clonazepam suppresses GABA $^{-}$ mediated inhibition in thalamic relay neurons through effects in nucleus reticularis. J. Neurophysiol. 71: 2576-2581, 1994.

JAHNSEN, H. AND LLINÁs, R. Electrophysiological properties of guinea-pig thalamic neurones: an in vitro study. J. Physiol. (Lond.) 349: 205-226, 1984a.

JAHNSEN, H. AND LlinÁs, R. Ionic basis for electro responsiveness and oscillatory properties of guinea-pig thalamic neurones in vitro. J. Physiol. (Lond.) 349: 227-247, 1984b.

KANDEL, A. AND BUZSÁKI, G. Cellular-synaptic generation of sleep spindles, spike-and-wave discharges, and evoked thalamocortical responses in the neocortex of the rat. J. Neurosci. 17: 6783-6797, 1997.

Leresche, N., Lightowler, S., Soltesz, I., JAssik-Gerschenfeld, D., AND CRunelli, V. Low-frequency oscillatory activities intrinsic to rat and cat thalamocortical cells. J. Physiol. (Lond.) 441: 155-174, 1991.

LUTHI, A. AND McCoRmick, D. A. Both electrophisiological and biochemical oscillations determine spindle wave periodicity. Soc. Neurosci. Abstr. 23: 708.10, 1997.

McCormick, D. A. And Huguenard, J. R. A model of the electrophysiological properties of thalamocortical relay neurons. J. Neurophysiol. 68: 1384-1400, 1992.

McCormick, D. A. AND PAPE, H. C. Properties of a hyperpolarizationactivated cation current and its role in rhythmic oscillation in thalamic relay neurons. J. Physiol. (Lond.) 431: 291-318, 1990.

Metherate, R. AND Ashe, J. H. Facilitation of NMDA receptor-mediated EPSP by paired-pulse stimulation in rat neocortex via depression of GABAergic IPSPs. J. Physiol. (Lond.) 484: 331-348, 1994.

Morin, D. AND SteRIADE, M. Development from primary to augmenting responses in primary somatosensory cortex. Brain Res. 205: 49-66, 1981.

Morison, R. S. AND DempSey, E. W. Mechanisms of thalamocortical augmentation and repetition. Am. J. Physiol. 138: 297-308, 1943.

Paré, D., Curró Dossi, R., and Steriade, M. Three types of inhibitory postsynaptic potentials generated by interneurons in the anterior thalamic complex of cat. J. Neurophysiol. 66: 1190-1204, 1991.
Pedroarena, C. And LlinÁs, R. Dendritic calcium conductances generate high-frequency oscillation in thalamocortical neurons. Proc. Natl. Acad. Sci. USA 94: 724-728, 1997.

Rispal-Padel, L., Harnois, C., and Troiani, D. Converging cerebellofugal inputs to the thalamus. I. Mapping of monosynaptic field potentials in the ventrolateral nucleus of the thalamus. Exp. Brain Res. 68: 47-58, 1987a.

Rispal-Padel, L., Troiani, D., ANd Harnois, C. Converging cerebellofugal inputs to the thalamus. II. Analysis and topography of thalamic EPSPs induced by convergent monosynaptic interpositus and dentate inputs. Exp. Brain Res. 68: 59-72, 1987b.

SANCHEZ-VIVES, M. V. AND MCCORMICK, D. Functional properties of perigeniculate inhibition of dorsal lateral geniculate nucleus thalamocortical neurons in vitro. J. Neurosci. 17: 8880-8893, 1997.

SANChEZ-VIVES M. V., BAL, T., AND MCCoRMICK, D. Inhibitory interactions between perigeniculate GABAergic neurons. J. Neurosci. 17: 88948908, 1997.

Soltesz, I., Lightowler, S., Leresche, N., Jassik-Gerschenfeld, D., Pollard, C. E., AND CRUNELli, V. Two inward currents and the transformation of low-frequency oscillations of rat and cat thalamocortical cells. J. Physiol. (Lond.) 441: 175-197, 1991.

STERIADE, M. The excitatory-inhibitory response sequence of thalamic and neocortical cells: state related changes and regulatory systems. In: $D y$ namic Aspects of Neocortical Function, edited by G. M. Edelman, W. E. Gall, and W. M. Cowan. New York: Wiley, 1984, p. 107-157.

Steriade, M., Curró Dossi, R., AND NuNEez, A. Network modulation of a slow intrinsic oscillation of cat thalamocortical neurons implicated in sleep delta waves: cortical potentiation and brainstem cholinergic suppression. J. Neurosci. 11: 3200-3217, 1991.

Steriade, M., Domich, L., OAKson, G., And Deschênes, M. The deafferented reticularis thalami nucleus generates spindle rhythmicity. J. Neurophysiol. 57: 260-273, 1987.

SteRIADE, M. AND TimOFEev, I. Short-term plasticity during intrathalamic augmenting responses in decorticated cats. J. Neurosci. 17: 3778-3795, 1997.

Steriade, M., Wyzinski, P., AND Apostol, V. Corticofugal projections governing rhythmic thalamic activity. In: Corticothalamic Projections and Sensorimotor Activities, edited by T. L. Frigyesi, E. Rinvik, and M. D. Yahr. New York: Raven Press, 1972, p. 221-272.

Thomson, A. M. Activity-dependent properties of synaptic transmission at two classes of connections made by rat neocortical pyramidal axons in vitro. J. Physiol. (Lond.) 502: 131-147, 1997.

Thomson, A. M., West, D. C., Hahn, J., and Deuchars, J. Single axon IPSPs elicited in pyramidal cells by three classes of interneurones in slices of rat neocortex. J. Physiol. (Lond.) 496: 81-102, 1996.

Timofeev, I., Contreras, D., AND Steriade, M. Synaptic responsiveness of cortical and thalamic neurones during various phases of slow sleep oscillation in cat. J. Physiol. (Lond.) 494: 265-278, 1996.

Timofeev, I. AND STERIADE, M. Cellular mechanisms underlying intrathalamic augmenting responses of reticular and relay neurons. J. Neurophysiol. 79: 2716-2729, 1998

Traub, R. D. and Miles, R. Neuronal Networks of the Hippocampus. Cambridge: Cambridge University Press, 1991.

TsOdYKs, M. V. AND MARKRAM, H. The neural code between neocortical pyramidal neurons depends on neurotransmitter release probability. Proc. Natl. Acad. Sci. USA 94: 719-723, 1997.

UlRich, D. AND Huguenard, J. R. GABA $A_{B}$ receptor-mediated responses in GABAergic projection neurones of rat nucleus reticularis in vitro. $J$. Physiol. (Lond.) 493: 845-854, 1996.

UlRich, D. AND Huguenard, J. R. Nucleus-specific chloride homeostasis in rat thalamus. J. Neurosci. 17: 2348-2354, 1997. 